\title{
THE EFFECT OF CONVERGENT-DIVERGENT NOZZLE PROFILE ON ITS PERFORMANCE
}

\author{
Arkan Kh. Al-Taie \\ arkanaltaie@yahoo.com
}

\author{
Hussien W. Mashi. \\ mshihuss@yahoo.com
}

\author{
Ali Muneeb Hadi \\ alimuneeb045@gmail.com
}

\section{University of Technology Dept. of Mechanical Engineering}

\begin{abstract}
The paper presents the effect of convergent-divergent nozzles profile across specified inlet pressures values from ( 1.5 bar- 4 bar), with constant back pressure of (1 bar). The flow of air through three convergent-divergent nozzles was studied theoretically. The flow was assumed to be one-dimensional, adiabatic and reversible (isentropic). The flow parameters like static pressure ratio and Mach number were analyzed. The flow parameters were obtained in term of area ratio along the nozzle. MATLAB code was built in order to find the Mach number along the nozzles, by using Newton-Raphson method. The shockwave position inside the nozzles was determined, using "analytic method". ANSYS fluent 18 was used to simulate the flow through the three nozzles. Twodimensional, turbulent and viscous models were utilized to solve the governing equations. K- $\varepsilon$ model was used to model the turbulent effect. The results concluded that, reduction in inlet pressure can not affect the flow upstream the throat. Also the shockwave appearance can be noticed by a sudden rise in static pressure associated with a sharp decrease in Mach number. Shockwave moves toward the throat by reduction the inlet total pressure .By comparison the static pressure distribution along the three nozzles where can be deduced that the profile has an effect on the flow character i.e. (static pressure Mach no). The best performance among the nozzles is the performance of nozzle (N1), which $(75 \%)$ of its length work as nozzle at the lowest inlet pressure of (1.5bar) while (44\% and $60 \%$ ) of the nozzles length for (N2 and N3) respectively work as the nozzle.
\end{abstract}

\section{KEY WORDS: convergent-divergent nozzle, Mach number, shockwave, isentropic flow.}

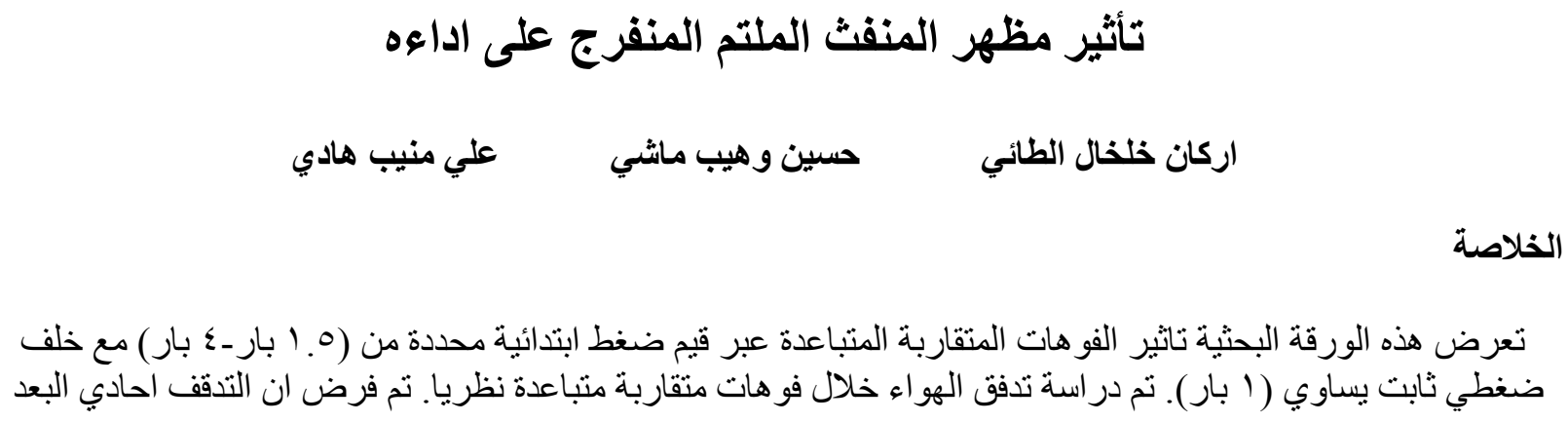

Received : 2017 -11 - 19

Accepted : 2018 - 3 - 5 


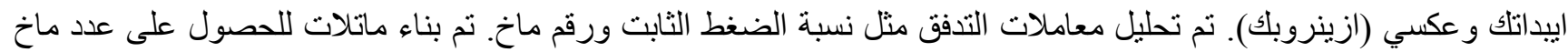

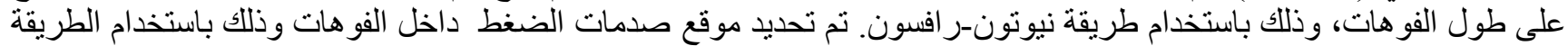



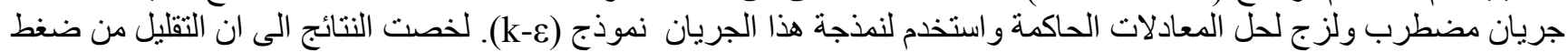

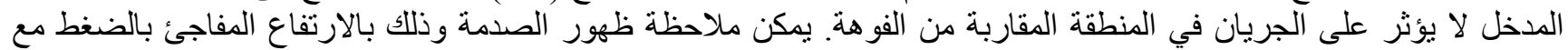

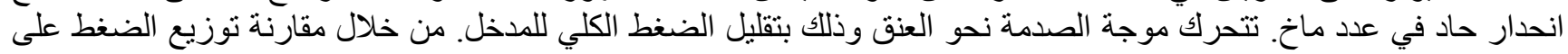

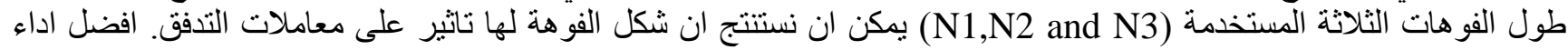

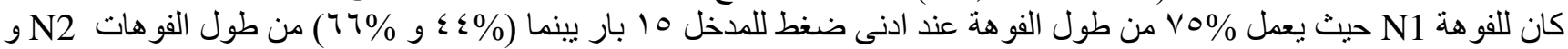
N3

\section{INTRODUCTION}

The nozzle is a duct of smoothly varying cross sectional area in which a steadily flowing fluid can be made to accelerate by a pressure drop along the inlet. There are many applications needed to use the nozzles i.e. steam and gas turbines, jet in rocket motors etc. The properties distribution i.e. (static pressure, Mach number, density etc.) of gas flow through C.D nozzles are carried out using ANSYS fluent 12.0 by Nazar Muneam [2013] to solve quasi-one dimensional nozzle flow. The decreasing in the back pressure has no effect on the conditions upstream the throat, the nozzle therefore, chocked. The shockwave can cause an increase in the pressure, density and temperature while causing a decrease in the velocity and Mach number to subsonic. By reducing the back pressure the shockwave move further down the divergent part of the nozzle. Biju Kuttan and Msajesh [2013] conducted the CFD analysis of rocket engine nozzle to study the phenomena of supersonic flow through it at different divergent angles. ANSYS fluent software was used to solve the governing equations. The flow parameters were analyzed by using twodimensional and axis-symmetric model. Stander K- $\varepsilon$ model was used to consider the viscous effect. This research concluded that the exist Mach no. rises with rising the divergent angle. It is found that at divergent angle of $4^{\circ}$ the Mach no. is 2.2 and at $15^{\circ}$, the Mach no. is equal to 4.82 . The throat Mach no. goes on increasing with the rise in divergent angle. It was increased from 0.826 at angle of $4^{\circ}$ to 1.25 at $15^{\circ}$. The static pressure decreases with increasing the divergent angle. Oblique shockwave moves toward the nozzle exist by increasing the divergent angle. The first shock appeared at $1 \mathrm{~m}$ from the nozzle inlet, when the divergent angle was $4^{\circ}$. When the angle of $7^{\circ}$, the shock occurred at $1.25 \mathrm{~m}$ but, the shock formed at $1.6 \mathrm{~m}$ from inlet at $13^{\circ}$. The divergent angle of $15^{\circ}$ could be considered as a good design because the shock is completely eliminated from the nozzle. Kunnal pansari and S.A.K Jilani [2013] analyses the performance and the properties of the flow through a C.D nozzle. Two numerical methods were used, hit and trial method and analytic methods to determine the location of the shockwave. Shock location moves towards exist by reducing $\mathrm{t}$ exist pressure ratio $(\mathrm{Pe} / \mathrm{Po})$. Also for constant area ration shock location varies significantly with pressure ratio. P. Parthiban et al. [2015], A two dimensional model was used for the analysis of finite volume method in ANSYS fluent software. Steady state, density based inviscid model was utilized in ANSYS fluent. By using optimization technique of taguchi design and analysis method DOF the optimum parameters value of static pressure and Mach number for various configuration of nozzles were being analysis and satisfy the thrust requirements for the nozzles. Shyamshankar and M. B Sankar V. [2015] analyzed the compressible flow through the convergent-divergent nozzle using the CFD code Fluent. The goal of this research was to investigate the supersonic C-D nozzle flow for rising nozzle pressure ratio (NPR) i.e. (the ratio of the outlet pressure to ambient pressures through CFD. A wide range of NPR values was achieved, by changing inlet and outlet pressures. Shockwave attached to outlet plane of the nozzle below NPR value of 0.454 . Below 2.2 bar of inlet pressure, shockwave equal to exist of the nozzle at 4.5 bar of inlet pressure to 1.01325 bar of outlet pressure. Mach no. is equal to 0.48 , at inlet pressure of 2.2 
bar to 1.01325 bar of outlet pressure. Between 4.7 bar to 2.2 bar of inlet pressure, exist Mach no is reduced due to shockwave. The exist Mach no. is within 2.1 to 2.19, from 17 bar to 4.7 bar of inlet pressure. Nozzle is chocked at inlet pressure of 2.2 bar and ambient pressure of 1.01325 . B. V. V. Naca Sudnakar et al. [2016] studying the behavior of flow across convergent divergent nozzle by resolving for various parameters i.e. pressure, temperature and velocity by using CFD software. This software was ANSYS fluent to solve two dimensional with K. $\varepsilon$ turbulent model. Also analytic calculations were made. The results acquired theoretically by using isentropis calculation almost identical to those acquired by CFD (computational fluid dynamics). As well as the same conclusions were obtained from. Syed Sameer and Kal Yana Kumar [2017]. In this work supersonic flow through the rocket nozzle has been simulated using numerical method. The parameters like Mach number, static pressure and shocks are observed for conical and contour nozzles using axi-symmetric model in ANSYS FLUENT 14® software. The occurrences of shocks for the conical nozzles were observed along with the other parameters for various divergent angles. The parameters under observation are compared with that of contour nozzle for respective divergent angles by maintaining the inlet, outlet and throat diameter and lengths of convergent and divergent portions as same. The convergent portion and throat diameter are kept constant across the cases. The phenomenon of shock was visualized and the results showed close resemblance in formation of Mach disk and its reflection patterns as reported in various experimental studies on expansion in conical C-D nozzles with lower divergent angles. No occurrence of shocks is observed with higher divergent angles. Results depicted higher exit velocity and higher degree of flow separation with contour nozzles compared to that of with corresponding conical nozzles. This research conclude that Validation of numerical results show that even by restricting the computational domain to exit of the nozzle acceptable results can be obtained. From the Mach number graph it is shows that velocity increases from inlet to outlet. Esam Jassim [2017] simulated a three-dimensional C.D nozzle by using fluent code. Six different shapes of nozzle (rectangular, triangular, elliptical, circular, hexagon and pentagon) were a numerically simulated to demonstrate the location of shock wave. The pressure ratio carves changed from 1.2 to 2 . The results showed that in elliptical nozzle shockwave has the farthest distance from the throat among the others. Hexagon nozzle would be the farthest as NPR rises.

\section{THEORETICAL WORK}

Isentropic flow calculations of three different profile nozzles will be performed. Also, a simulation of steady flow of air through C-D nozzle using CFD code ANSYS fluent 18 will be done.

\section{Isentropic Calculation}

This paper presents the theoretical aspects of air flow in convergent-divergent nozzle. Isentropic flow calculations of three different profile nozzles (N1, N2 and N3) as shown in figure

(1) is performed. The shape of the profile of the nozzles was taken from Mashi H. W. and Alrabii

S. A. [2012]. The curve equations of each nozzle are as the following:

$$
\begin{aligned}
& y=2 * 10^{-10} x^{6}+7.98 * 10^{-8} x^{5}+1.361 * 10^{-5} x^{4}+9.5 * 10^{-4} x^{3}+0.0226 x^{2}+041 x \\
& +38.161(N 1) \\
& y=-3.1 * 10^{-11} x^{6}+2.24 * 10^{-8} x^{5}-6.08 * 10^{-6} x^{4}+7.522 * 10^{-4} x^{3}-0.374 x^{2} \\
& +0.0342 x+37.25(N 2) \\
& y=8.91 * 10^{-11} x^{6}-4.032 * 10^{-9} x^{5}+6.633 * 10^{-6} x^{4}-4.87 * 10^{-4} x^{3}+0.02 x^{2} \\
& -0.965 x+38.103(N 3)
\end{aligned}
$$


Compressible isentropic flow through C-D is considered. Friction and heat transfer are nonexistent in isentropic flow also changes in potential energy and gravitational forces are negligible

One dimensional steady state is assumed in equations. Variations in flow properties are brought about by area change.

\section{Equations of motion:}

For one dimensional steady flow through a varying area channel, the continuity equation is

$\iint_{c . s .} \rho V \cdot d A=\dot{m}_{o u t}-\dot{m}_{\text {in }}=0$

Thus, the mass flow rate, $\boldsymbol{m}(\mathrm{Kg} / \mathrm{s})$ is constant at all sections of the channel.

$\rho V A=\dot{m}=$ comstant

The differential form of continuity equation is:

$\frac{d \rho}{\rho}+\frac{d A}{A}+\frac{d V}{V}=0$

For steady flow, the momentum equation is:

$\sum F_{x}=\iint_{c . s .} V_{X}(\rho V d A)=\dot{m}\left(V_{o u t}-V_{\text {in }}\right)=0$

In absence of electromagnetic forces and with negligible friction, pressure force is only the force taking into account. After simplification, the steady one-dimensional momentum equation is called Euler's equation, which is valid for both constant and variable area geometries. The differential form is:

$d P+\rho V d V=0$

The energy equation with negligible potential energy, no heat transfer and no work, for onedimensional steady flow is:

$\iint_{c . s .}\left(h+\frac{V^{2}}{2}\right)(\rho V d A)=\dot{m}\left[\left(h+\frac{V^{2}}{2}\right)_{o u t}-\left(h+\frac{V^{2}}{2}\right)_{i n}\right]$

The differential form of energy equation is:

$d h+d\left(\frac{V^{2}}{2}\right)=0$

From Gibbs second identity

$T d s=d h-\frac{d p}{\rho}$

$\mathrm{ds}=0$ for isentropic flow then combining with $\boldsymbol{d h}=\boldsymbol{d} \boldsymbol{p} / \boldsymbol{\rho}$ then $(\boldsymbol{d p}+\boldsymbol{\rho} \boldsymbol{V} \boldsymbol{d} \boldsymbol{V}=\mathbf{0})$, which is the same equation (5)

\section{Equation of state:}

Equation of state is a relation between pressure, density and temperature of fluid. Air behavior is assumed as perfect gas so its equation of state is: 


$$
\boldsymbol{p}=\boldsymbol{\rho} \boldsymbol{R}
$$

\section{Velocity of sound:}

The sound wave is a weak compression wave across which only infinitesimal changes in fluid properties. The sound wave process is reversible and adiabatic so that it is isentropic process and velocity of sound may be more properly expressed as:

$a=\sqrt{\left(\frac{\partial p}{\partial \rho}\right)_{s}}$

By using the perfect gas law becomes

$$
a=\sqrt{\gamma R T}
$$

\section{Mach number:}

A non-dimensional parameter defined as the ratio of the speed of the gas divided by the local speed of sound. Mach number is the criterion for knowing the type of flow either subsonic or supersonic. It is an important parameter in study of compressible fluid flow

$$
M=\frac{V}{a}
$$

\section{Stagnation properties:}

Stagnation properties are useful in that they define a reference state for compressible flow. Total properties at a point in flow are the properties obtained by bringing the flow adiabatically to rest at that point. From previous equations a relationship between Mach number and stagnation to static temperature, pressure and density as well as area ratio can be obtained. These equations are:

$\frac{T_{o}}{T}=1+\frac{\gamma-1}{2} M^{2}$

$\frac{P_{o}}{P}=\left(1+\frac{\gamma-1}{2} M^{2}\right)^{\frac{\gamma}{\gamma-1}}$

$\frac{\rho_{o}}{\rho}=\left(1+\frac{\gamma-1}{2} M^{2}\right)^{\frac{1}{\gamma-1}}$

$\frac{A}{A^{*}}=\frac{1}{M}\left[\left(\frac{2}{\gamma+1}\right)\left(1+\frac{\gamma-1}{2} M^{2}\right)\right]^{\frac{\gamma+1}{2(\gamma-1)}}$

If the area ratio $\mathrm{A} / \mathrm{A}^{*}$ is known, the Mach number can be determined only through a root solving technique so Newton-Raphson method by using MATLAB code program as presented in the figure (2).

\section{Shock wave:}

Shock waves are compression waves that are seen in nozzles and occur under off-design operating conditions. Shock process is highly irreversible and causes sudden changes in flow properties. To find the properties behind the shock wave the next equations can be used:

$$
M_{2}^{2}=\frac{M_{1}^{2}+\frac{2}{\gamma-1}}{\frac{2 \gamma}{\gamma-1} M_{1}^{2}-1}
$$




\section{Then:}

$$
\begin{aligned}
& \frac{T_{2}}{T_{1}}=\frac{\left(1+\frac{\gamma-1}{2} M_{1}^{2}\right)\left(\frac{2 \gamma}{\gamma-1} M_{1}^{2}-1\right)}{\left[\frac{(\gamma+1)^{2}}{2(\gamma-1)}\right] M_{1}^{2}} \\
& \frac{P_{2}}{P_{1}}=\frac{2 \gamma M_{1}^{2}}{\gamma+1}-\frac{\gamma-1}{\gamma+1} \\
& \frac{P_{o 2}}{P_{o 1}}=\frac{A_{1}^{*}}{A_{2}^{*}}=\left[\frac{\frac{\gamma+1}{2} M_{1}^{2}}{1+\frac{\gamma-1}{2} M_{1}^{2}}\right]^{\frac{\gamma}{\gamma-1}}\left[\frac{1}{\frac{2 \gamma}{\gamma+1} M_{1}^{2}-\frac{\gamma-1}{\gamma+1}}\right]^{\frac{1}{\gamma-1}}
\end{aligned}
$$

Equation (21) represents the strength of the shockwave.

$$
\frac{P_{2}-P_{1}}{P_{2}}=\left[\frac{2 \gamma}{\gamma+1}\left(M_{1}^{2}-1\right)\right]
$$

All the above equations were taken from James E.John [2006].

\section{Determining the location of a normal shock in C-D nozzles:}

There are two procedures for locating a normal shock in C-D nozzles. For both methods, it is assumed that the area ratio (exit to throat), Ae/At and the pressure ratio $\mathrm{Po} / \mathrm{Pb}$ are specified. In one method (trial and error method), the location of the shock is specified as As/At. In this method the corresponding properties are determined based on this location. If the calculations do not agree with given information, the shock moves to new location and the calculations are repeated. James E.John [ 2006]. In second method (analytically method), which is used in the present work, the actual location of the shock is determined using the next procedure.

1. determined $M_{e}$ using next equation

$$
M_{e}^{2}=-\frac{1}{\gamma-1}+\sqrt{\left(\frac{1}{\gamma-1}\right)^{2}+\left(\frac{2}{\gamma-1}\right)\left(\frac{2}{\gamma+1}\right)^{\frac{\gamma+1}{\gamma-1}}\left(\frac{P_{o 1}}{p_{b}}\right)^{2}\left(\frac{A_{t}}{A_{e}}\right)^{2}}
$$

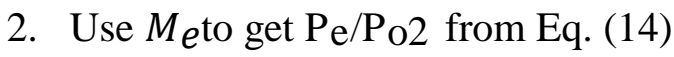

3. Since $M_{e}<1, P_{e}=P_{b}$, so from the product $\left(P_{b} / P_{o 1}\right)\left(P_{o 2} / P_{e}\right)=P_{o 2} / P_{o 1}$.

4. $M_{1}$ is determined by using Newton-Raphson method to solve Eq. (20), since $P_{o 2} / P_{o 1}$ is obtained from step 3.

5. From Eq. (16), $A_{s} /_{A_{t}}=A_{s} / A_{1}^{*}$ can be determined. 


\section{CFD WORK:}

To simulate the air flow through different profile C-D nozzles, ANSYS fluent (18) is used. The variation of inlet pressure effect at constant back pressure is present too.

The analysis procedure that is used in the ANSYS is stated in table (1).

\section{Computational run:}

The governing equations are non-linear (and coupled) so before getting a converged solution, several solution loops iterations should be performed. The procedures that each iteration is consisted of, are illustrated in figure (3) and briefed as below:

1. The fluid properties are updated based on the current solution and will be updated depending on the initialized solution if the calculation has just stated.

2. The continuity, momentum and energy and species equations are solved at the same time.

3. Scalars equations such as turbulence are solved, so the other variables beforehand updated values are used.

4. The source terms in the suitable continuous phase equations are updated when including the interphase coupling.

5. The equation set is checked for convergence.

These steps are stopped when the convergence criteria are met. ANSYS theory guide [2013]

\section{RESULTS}

\section{Isentropic Results}

Figure (3) shows the Mach number distribution with dimensionless axial distance for nozzle (N1). Because of reduction in cross-sectional area of the convergent-section, the Mach number increases, and the flow is subsonic. At throat the flow becomes sonic and the Mach number value is equal to unity. When the flow passes through the divergent-section becomes supersonic, because widen in the area causes increasing in velocity, so the Mach number value become more than unity. It can be observed that the Mach number for all cases increases in convergent part from subsonic to sonic at the throat then to supersonic at the divergent part till the shockwave's position which returns to subsonic after the shock and that because the flow throughout the shockwave changes some of its kinetic energy into static pressure. For nozzle (N1), inlet pressure was varied in range (1.5 bar -4 bar) bar with constant atmospheric back pressure. Figure (4) describes the varying of static pressure ratio against the dimensionless axial distance of nozzle (N1). In convergent the static pressure ratio decreases due to increasing in velocity and continues in decreasing through the divergent part till reaching the shockwave position, where the velocity drop, therefore the static pressure ratio rise suddenly and continues in rising to the nozzle exit. It can be noticed in all cases that the variation of static pressure ratio is similar in convergent part, throat and divergent part until reaching the shockwave where its location moves backward to the throat with lowering the total inlet pressure. For nozzle (N2), figure (5) shows the Mach number distribution against the axial dimensionless distance for the variations of inlet pressure. The narrowing in the area of convergent part cause increasing in the Mach no. and continues in increasing till the throat where its value is equal to unity. In the divergent part, widen in the area leads to rise the velocity and the flow become supersonic. The Mach number does not change in convergent zone and throat where its value becomes unity in all cases; and divergent zone until comes to a shockwave where the Mach number is lowering sharply and the flow become subsonic. The Mach number stills in lowering after shock to the end of the nozzle. When the inlet pressure is (4 bar) the flow continues in acceleration across the whole length of the nozzle. The flow velocity reaches to its maximum value of Mach number equal to (3.08) at exist. The influence of the varying of inlet total pressure in range ( 1.5 bar - 4 bar) with constant back pressure which equal to atmospheric pressure on nozzle (N2) is presented in Figure (6) which illustrates the distribution of static pressure ratio against the dimensionless axial distance for all inlet total pressures. It 
shows the effect of its variation. It can be observed that in spite of lowering the inlet pressure the distribution of pressure ratio is the same in convergent part which is lowering due to increasing in velocity and in the divergent part carrying on decreasing until reaches the position of shockwave where intensive rise in pressure ratio happens and that because across the shock the flow changes some of its kinetic energy into static pressure. The shockwave position moves upstream as the inlet pressure is lowered. But when the inlet pressure is (4bar) no shock appears so the expansion occurs along the whole length of the divergent part. Figure (7) clarifies the distribution of static pressure ratio along the nozzle (N3) for all initial total pressure. The pressure ratio is identical for all case in the zone before the shock. After intensive rise in pressure the pressure ratio stays in rising to the nozzle exit. Also the same observation can be noted in figure (8) which shows the Mach number distribution along the nozzles for all cases in which the Mach number is increasing before the shockwave and after that stay to decrease till the nozzle's exist.

\section{NUMERICAL RESULTS}

The field parameters such as Mach number, static pressure and total pressure distribution in the CD nozzles with different profiles are performed by using ANSYS fluent (18.0). The CFD results will include the influence of varying initial pressure on the field parameters. The effect of reducing inlet stagnation pressure from (4) bar to (1.5) bar on the flow through the convergentdivergent nozzle (N1) will be presented in figures from (9) to (11), which show the static pressure contours and Mach number contours. From Mach number contour in figure (9a) when the initial total pressure is (4) bar it can be seen that the flow is subsonic and accelerating due to reduction in the cross sectional area in the convergent section associated with decreasing in static pressure as shown in figure (9b). In throat regime the Mach number is equal to unity referring to chocking condition in nozzle happened. The flow continues in accelerating after throat which becomes supersonic in the divergent section, where the static pressure is still lowering. Because of shockwave occurs in nozzle, reduction is in Mach number, however strong rising is in static pressure and all these are an indication of shockwave appearance in the divergent part. Contours of static pressure, Mach number and total pressure of cases when inlet total pressure is (3 and 2) bar respectively are shown in figures from (10) to (11). From these figures, it can be recognized that the behavior of Mach number and static pressure is similar in all cases unless the shockwave's location moves backward to the throat by reducing the initial pressure. Static pressure and Mach number contours are presented in figures from (12) to (13). The general behavior of flow passing nozzle (N2) is similar to its behavior through nozzle (N1). That is clear from the contours of static pressure where it is still in decreasing in the zone before the shockwave that causes a sudden rise in pressure and a sharp decrease in Mach number. Also, Mach number contours refer to that the flow is expanding and accelerating in convergent part and converts from subsonic to sonic at throat, further expansion takes place in divergent part where the flow become supersonic. After the shockwave, the flow turns to subsonic and decelerates in the remaining part of the nozzle that works as diffuser. Lowering the inlet total pressure causes moving the shockwave inside the nozzle. The decreasing of inlet pressure influences on the flow passing through the convergent- divergent nozzle (N3) clarified in figures from (15) to (17), which include the contours of static pressure and Mach number; for each inlet pressure. The flow through this nozzle has the same general behavior of flow passing through the nozzles (N1) and (N2). So, the same explanation in previous nozzle can be submitted on this nozzle. Figure (18) illustrates the isentropic flow through the three nozzles at six inlet total pressures between (1.5bar and 4 bar). This figure illustrates the static pressure ratio distribution against the dimensionless axial distance of the nozzles. The flow behavior in convergent section was similar for the three nozzles. The flow velocity is equal to sonic velocity at the throat. The flow behavior is also similar in divergent section before the shockwave location. It can be recognized in nozzle (N1) no shock appears inside the nozzle when the inlet pressure was (4bar) while appears in nozzles (N1 
and N2). These comparisons among the nozzles at different inlet pressures show the effect of the nozzle geometry on the flow behavior. It can be obtained that the best nozzle works at those inlet pressures is nozzle (N1) because no shockwave appears through this nozzle when the inlet pressure was (4bar). The location of shock at each specified inlet pressures is the nearest to the exist also the shockwave strength is the lightest. Figure (19) demonstrates the numerical CFD static pressure distribution verse the axial dimensionless distance of the three nozzles. The same recognitions in the isentropic can be found here and supports those recognitions. From the CFD results, it can be observed that at low pressure ratio flow separation occurred after the shockwave, due to the effect of viscosity and that is clear in all the nozzles when the inlet pressure was ( 2 bar). Figures from (18) to (20) show the comparison between the CFD results and isentropic results for each nozzle at different inlet pressures. These figures illustrate the static pressure distribution along the nozzles center-line against the axial distance. It can be observed that the flow action is the same in all cases generally. The CFD and isentropic results are approximately identical in convergentsection, throat and divergent-section, unless the position of the shockwave shifts slightly, because that the increase in static pressure in isentropic flow due to shock takes a straight line while in the CFD, this increase occurs gradually with a slope because of the friction effect. Figure (21) illustrates the strength of the shockwave for each nozzle against the inlet total pressures where can be observed that the strength increases with rising of inlet total pressure. Also influence by the exit area ratio of the nozzles in which increase by increasing the area ratio at specified inlet pressure. Where nozzle (N1) has the smallest area ratio of (4.67) while nozzle (N2) has area ratio of (5.67) and the biggest area ratio is for nozzle (N3) that equal to (6). Because of no shockwave occurred in nozzle (N1) when the inlet pressure was (4bar) the curve of the strength ended at $\left(\mathrm{P}_{\mathrm{O}}=3.5\right.$ bar). By plotting the shockwave locations $\left(\mathrm{As}_{\mathrm{s}} / \mathrm{At}\right.$ ) against the exit area ratio (Ae/At) for each nozzle at variation inlet pressure as in figure (22) where can notice that the locations of shockwave influenced by exist area ratio of the nozzle where increase in exist area ratio associated with increasing shockwave location $\left(\mathrm{A}_{\mathrm{S}} / \mathrm{At}_{\mathrm{t}}\right)$ at specified inlet pressure. After showing how the strength and the location of the shockwave vary with the nozzle exit area ratio and pressure ratio, figure (23) illustrates the isentropic flow through the three nozzles at six inlet total pressures between (1.5bar and 4 bar). This figure illustrates the static pressure ratio distribution against the dimensionless axial distance of the nozzles. The flow behavior in convergent section was similar for the three nozzles. The flow velocity is equal to sonic velocity at the throat. The flow behavior is also similar in divergent section before the shockwave location. It can be recognized in nozzle (N1) no shock appears inside the nozzle when the inlet pressure was (4bar) while appears in nozzles (N1 and N2). These comparisons among the nozzles at different inlet pressures show the effect of the nozzle geometry on the flow behavior. It can be obtained that the best nozzle works at those inlet pressures is nozzle (N1) because no shockwave appears through this nozzle when the inlet pressure was (4bar). The location of shock at each specified inlet pressures is the nearest to exist also the shockwave strength is the lightest.

\section{CONCLUSIONS}

From this work the following conclusion are withdrawn:

1. The inlet total pressure has direct proportional with the strength of the shockwave.

2. The exist area ratio (Ae/At) affects in the strength of the shock in which small area ratio has low shockwave strength as compared with larger one at specified inlet pressure.

3. As exist area ratio (Ae/At) increases the location of the shockwave increases too at specified inlet total pressure.

4. At specified exist area ratio (Ae/At) the increasing in inlet pressure cause increase in shockwave location $\left(\mathrm{A}_{\mathrm{S}} / \mathrm{At}_{\mathrm{t}}\right.$ ) and that mean the shockwave moves toward the exist of the nozzle. 
5. The best performance among the nozzles is the performance of nozzle (N1) in both isentropic and numerical results.

6. Because of over-expansion the shockwave exists in the divergent part which divides the nozzles into two zones: The first zone is behind the shock, where the flow is expanding and accelerating from subsonic in convergent part to sonic velocity at throat and then to supersonic. The second zone is after the shock where the flow decelerates and becomes subsonic associated with increasing in static pressure; this zone works as diffuser. 


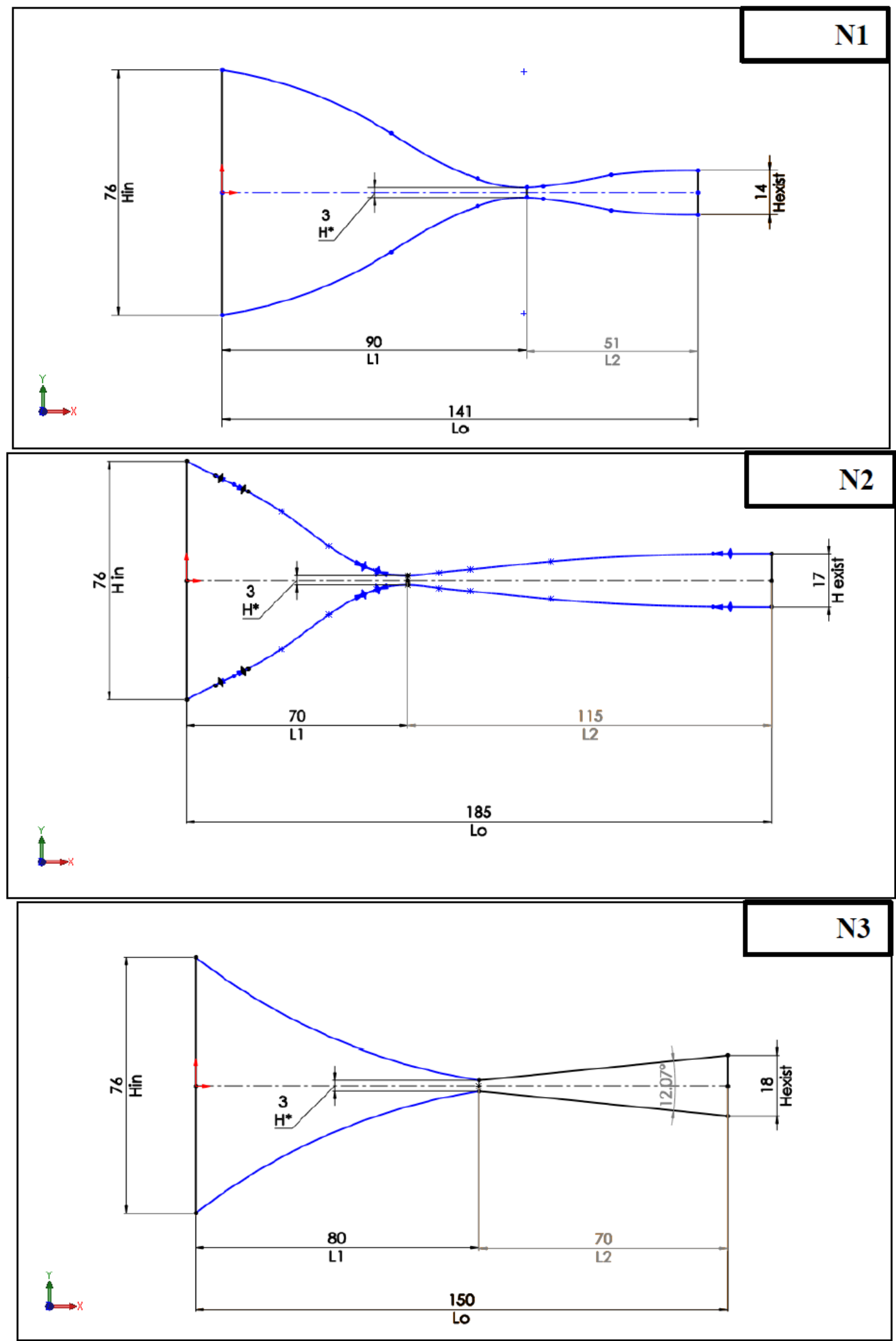

Figure (1): Shape of the nozzles with their dimensions.

(All dimensions in millimeter). 


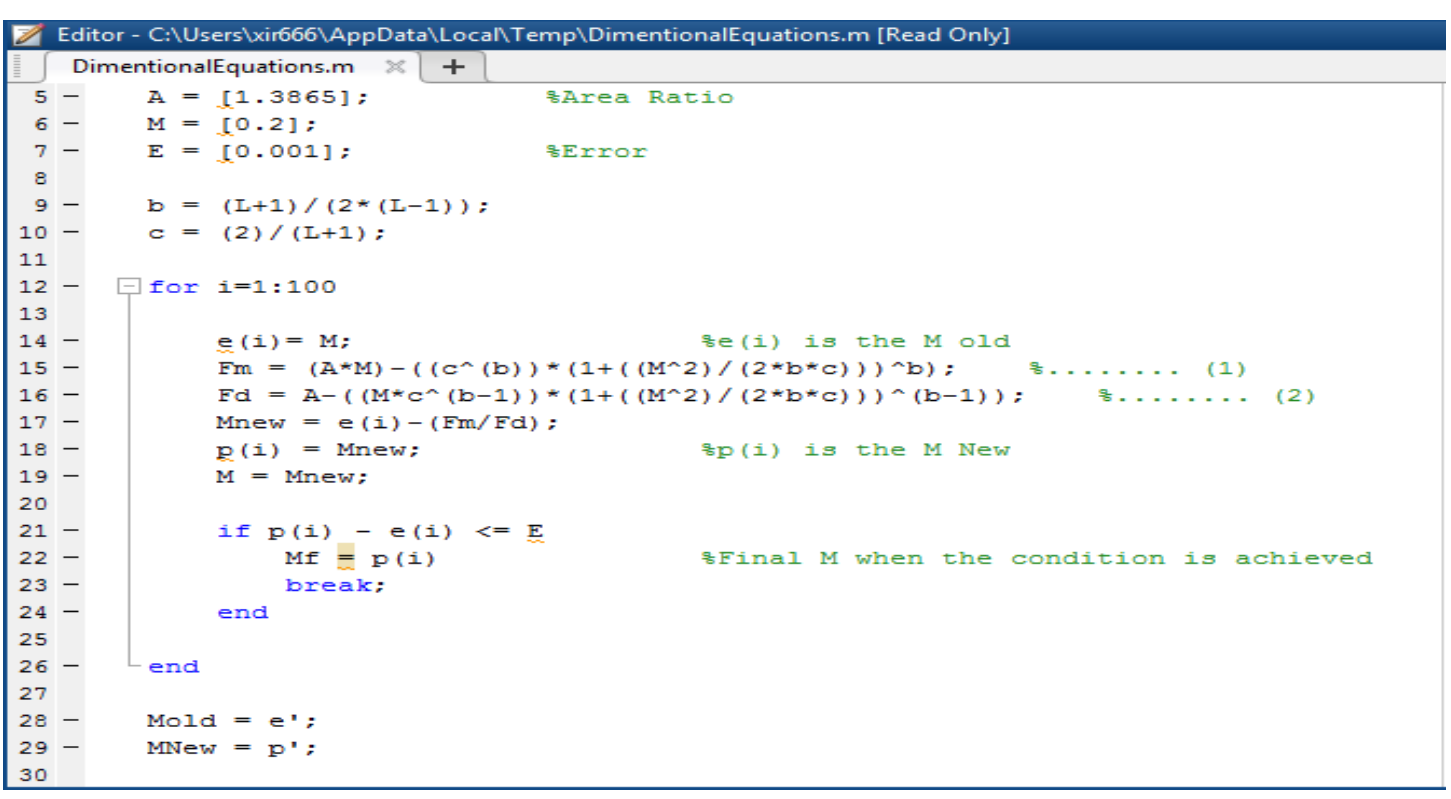

Figure (2): MATLAB code.

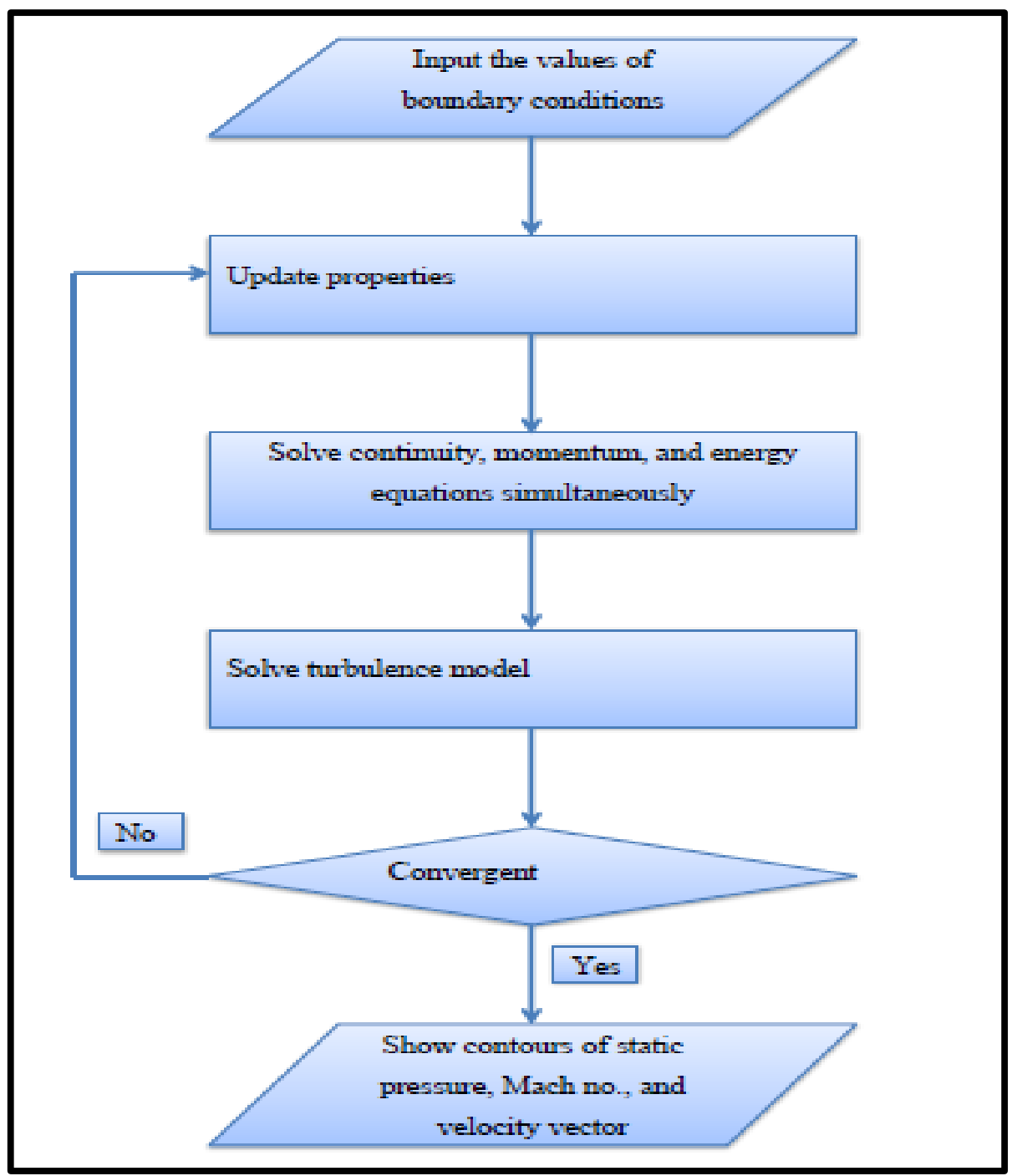

Figure (3): Flow chart of the density-based method [37] 


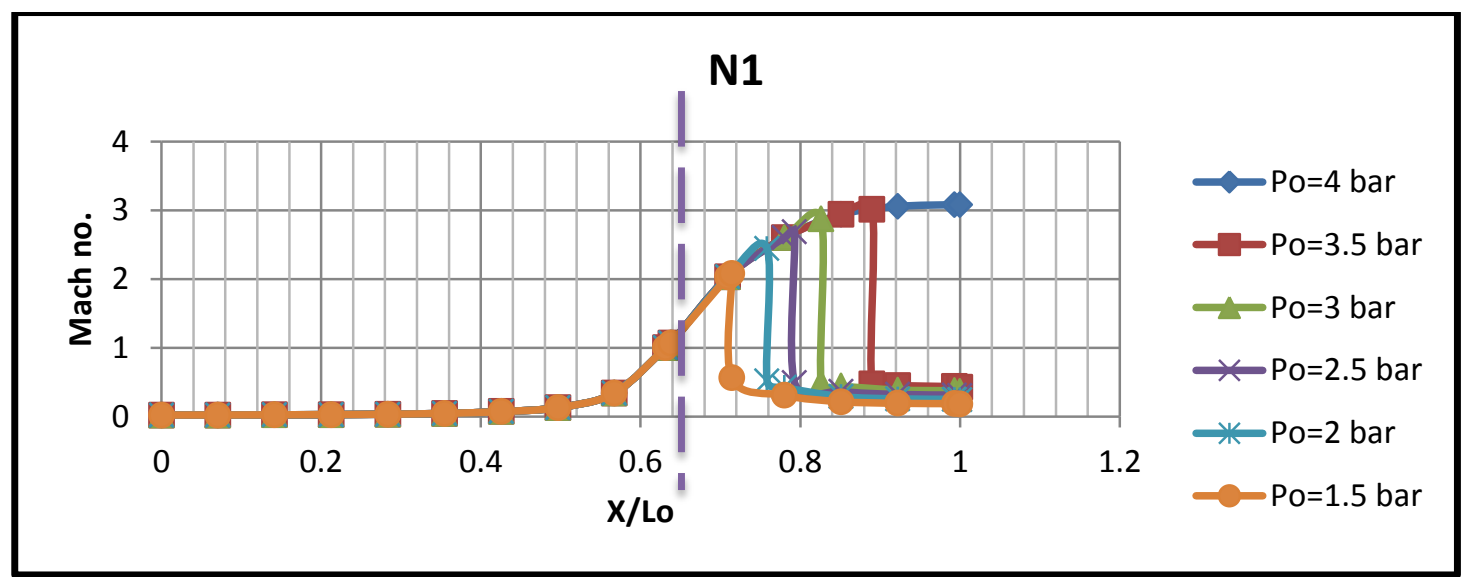

Figure (4): The isentropic Mach No. distribution for all cases.

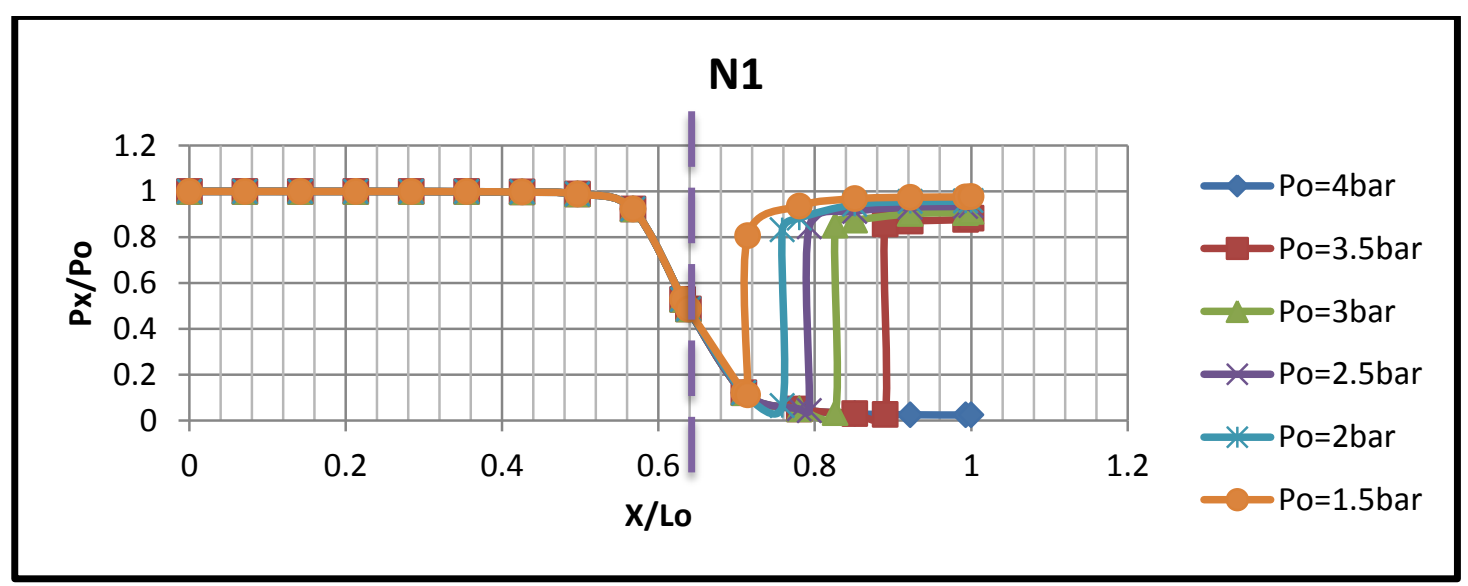

Figure (5): the isentropic pressure ratio distribution for all cases.

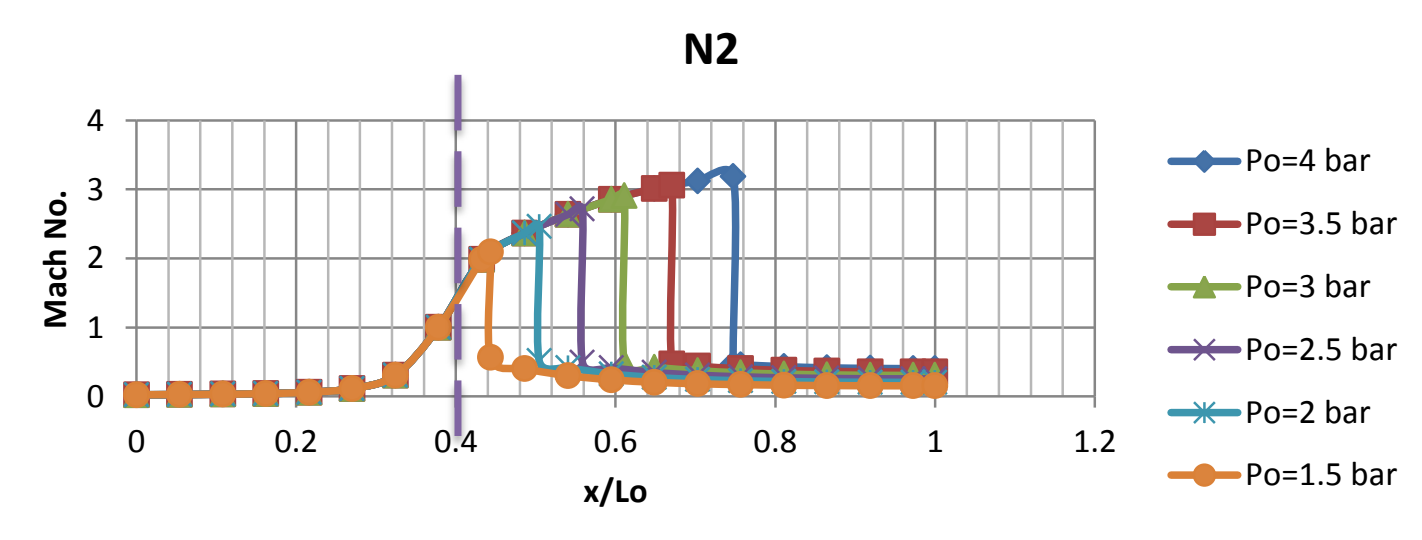

Figure (6): The isentropic Mach No. distribution for all cases. 


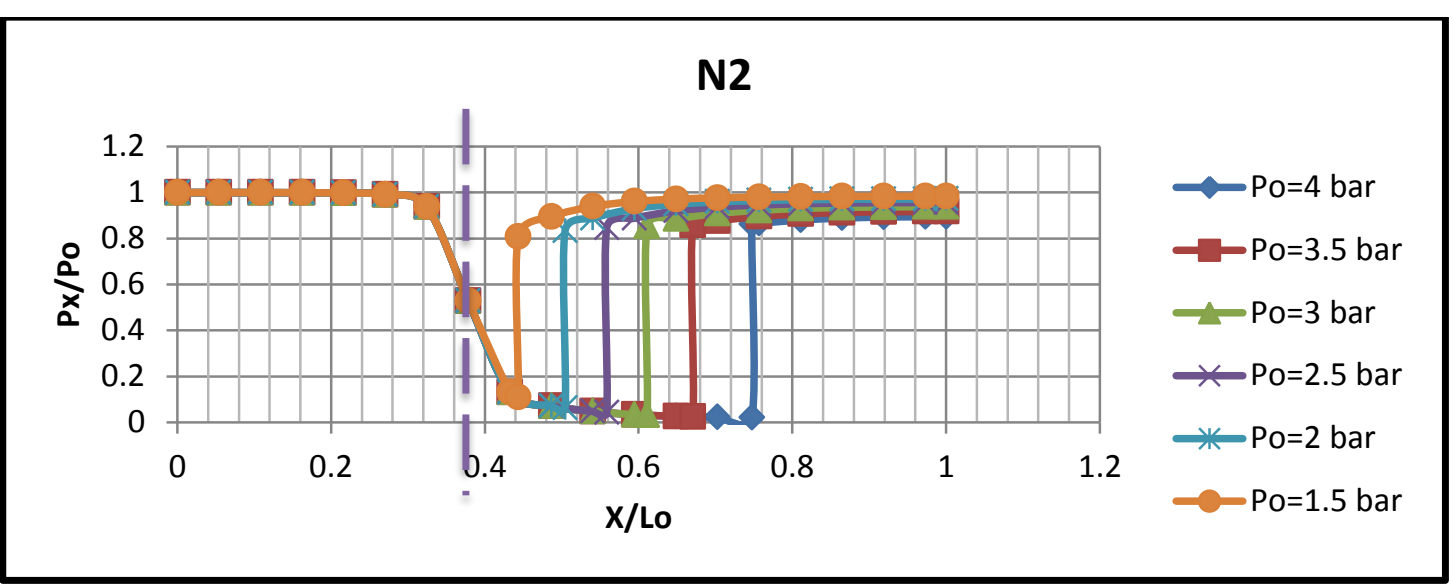

Figure (7): The isentropic pressure ratio distribution for all cases.

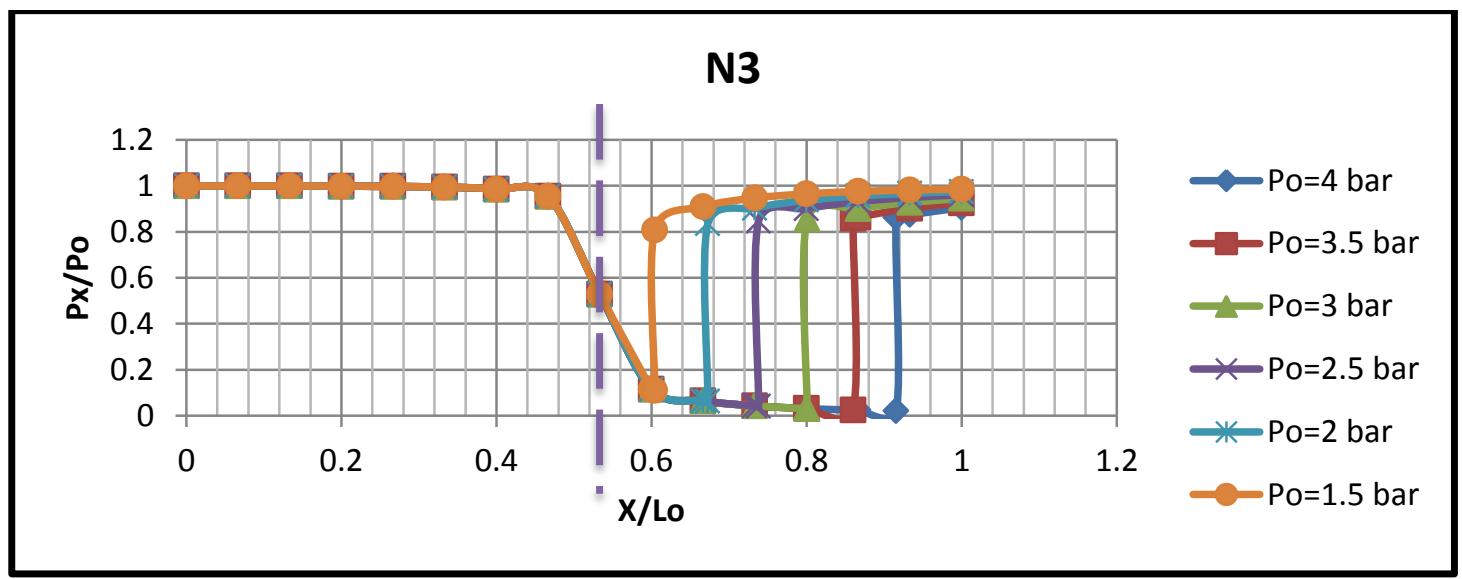

Figure (8): The isentropic pressure ratio distribution for all cases.

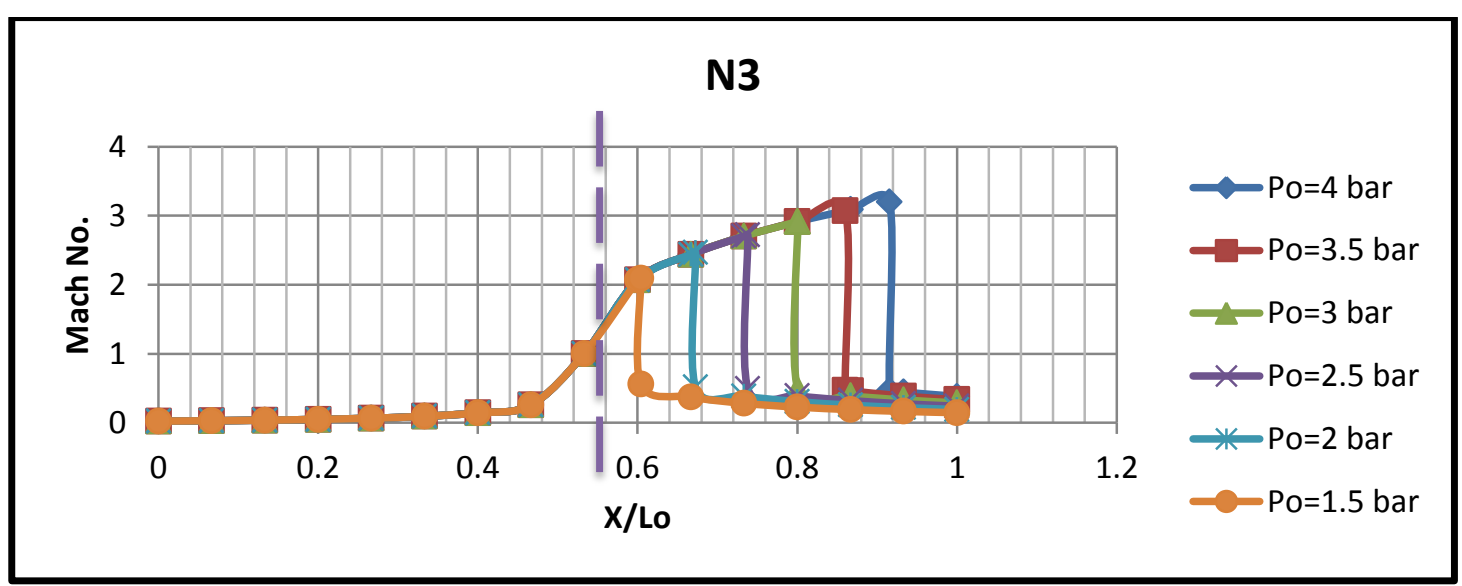

Figure (9): The isentropic Mach No. distribution for all cases. 


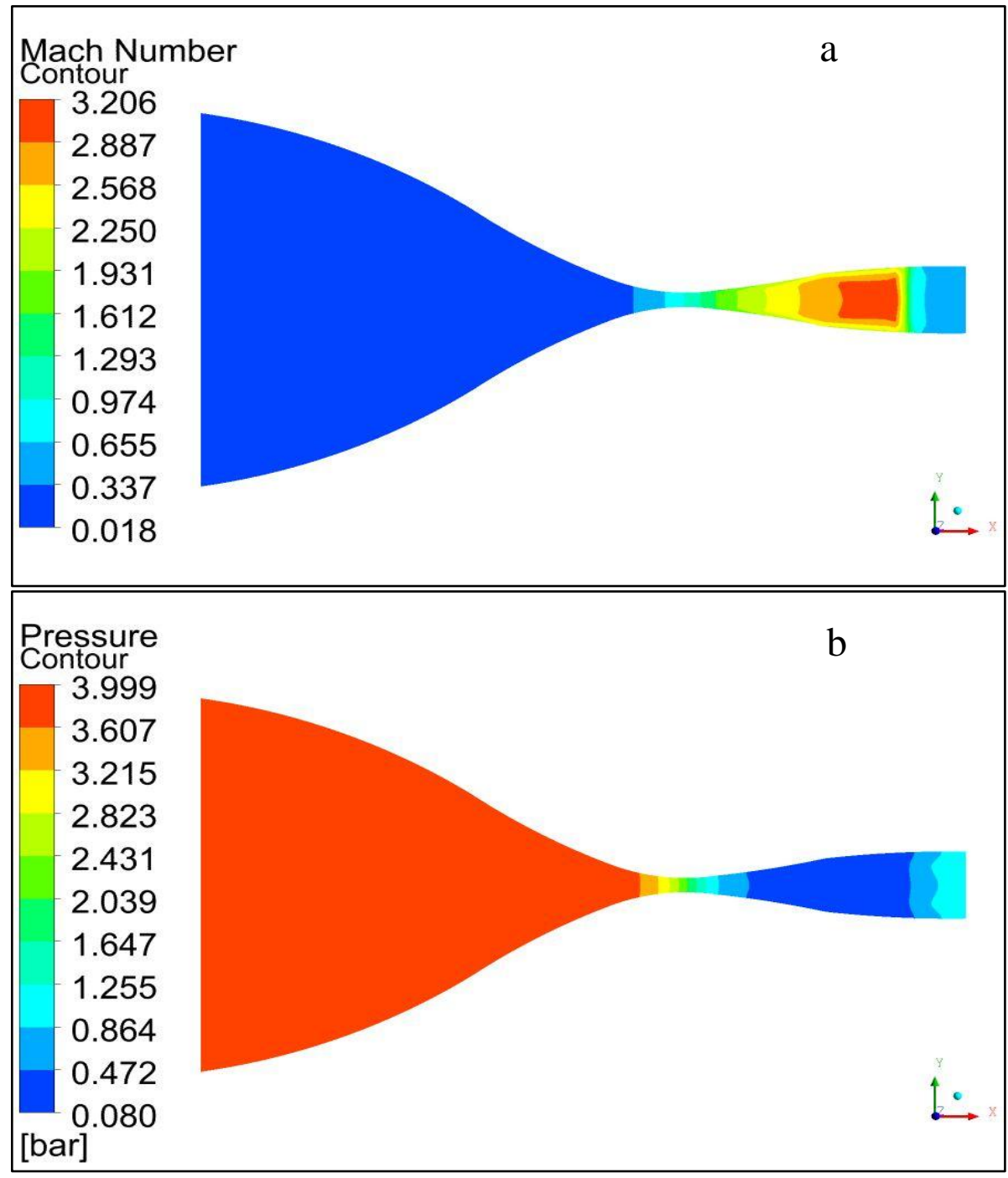

Figure (10): $\left(\mathrm{P}_{\mathrm{o}}=4\right.$ bar, $\mathrm{P}_{\mathrm{b}}=1$ bar).

(a) Mach No. contour. (b) Static pressure contour. 


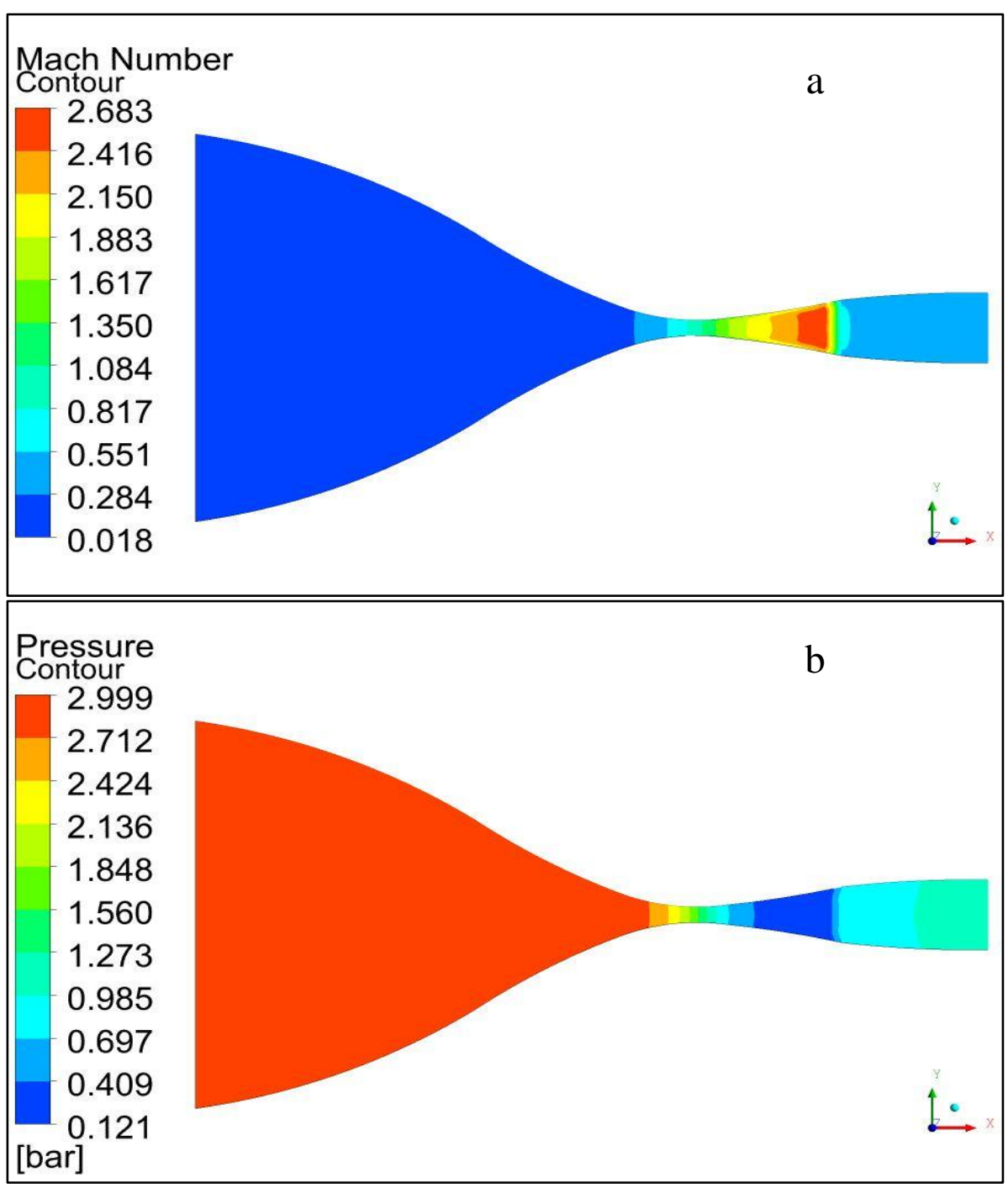

Figure (11): $\left(\mathrm{P}_{\mathrm{o}}=3\right.$ bar, $\mathrm{P}_{\mathrm{b}}=1$ bar).

(a) Mach No. contour. (b) Static pressure contour. 


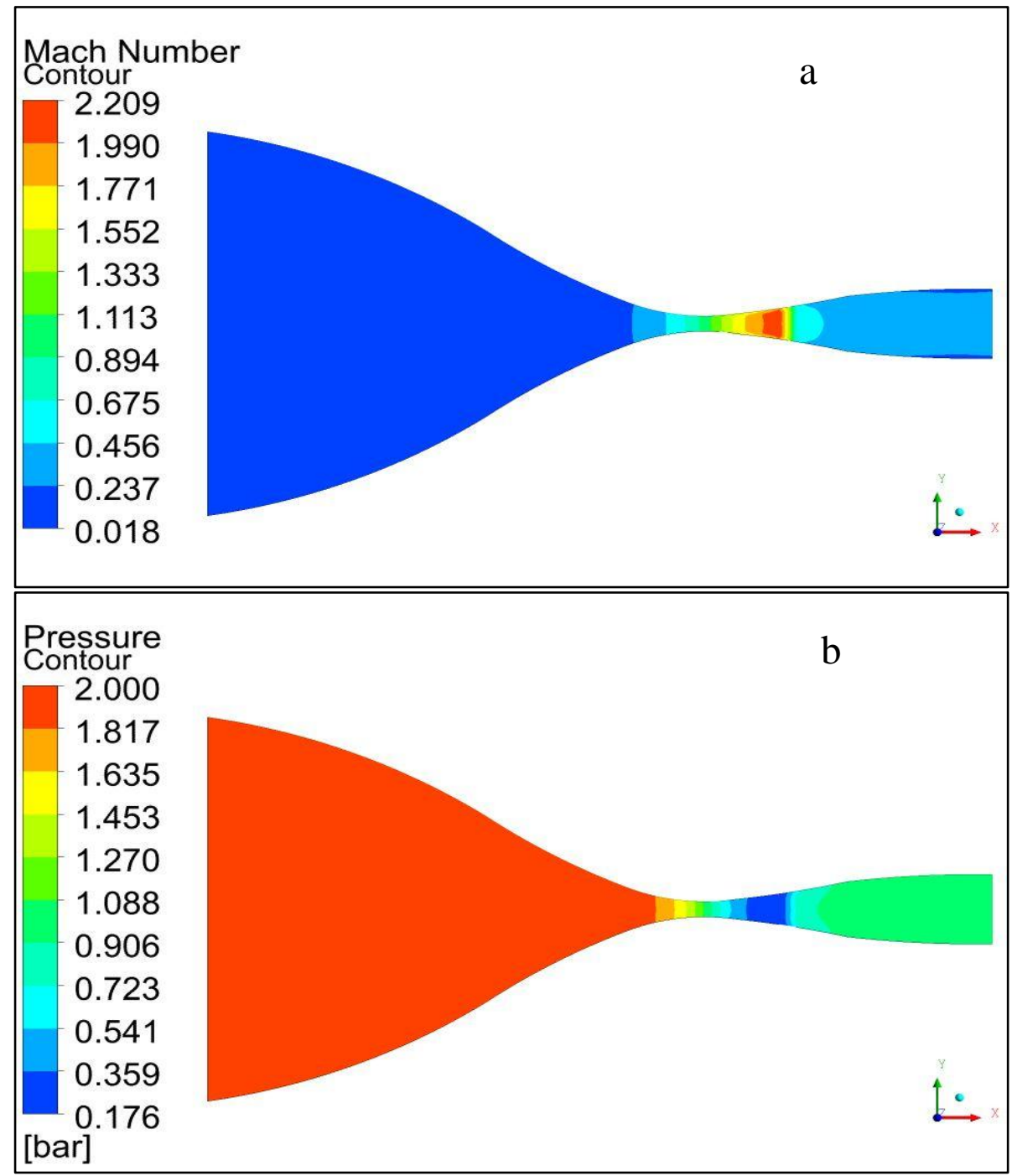

Figure (12): ( $\mathrm{P}_{\mathrm{o}}=2$ bar, $\mathrm{P}_{\mathrm{b}}=1$ bar).

(a) Mach No. contour. (b) Static pressure contour. 


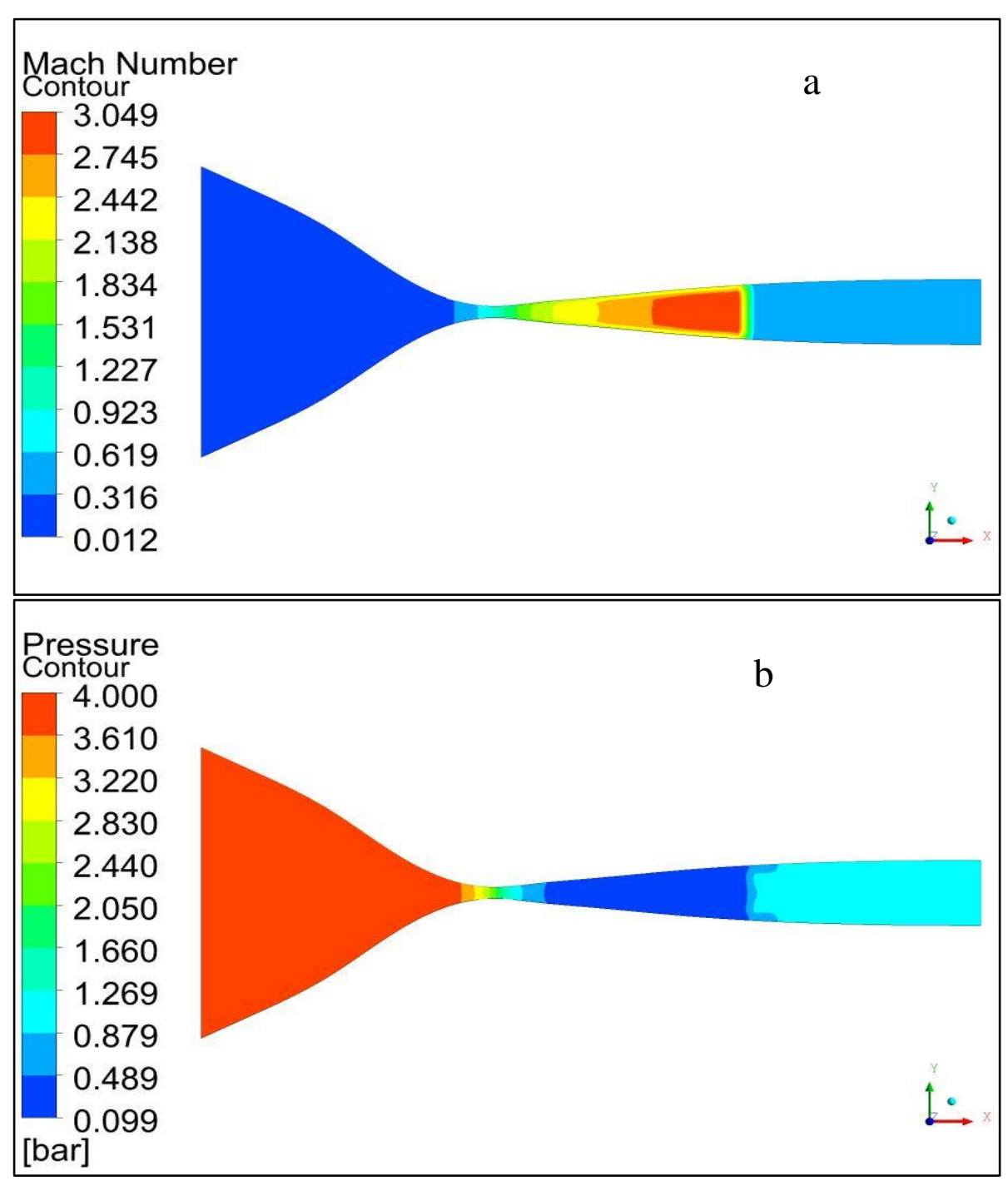

Figure (13): $\left(\mathrm{P}_{\mathrm{o}}=4\right.$ bar, $\mathrm{P}_{\mathrm{b}}=1$ bar).

(a) Mach No. contour. (b) Static pressure contour. 


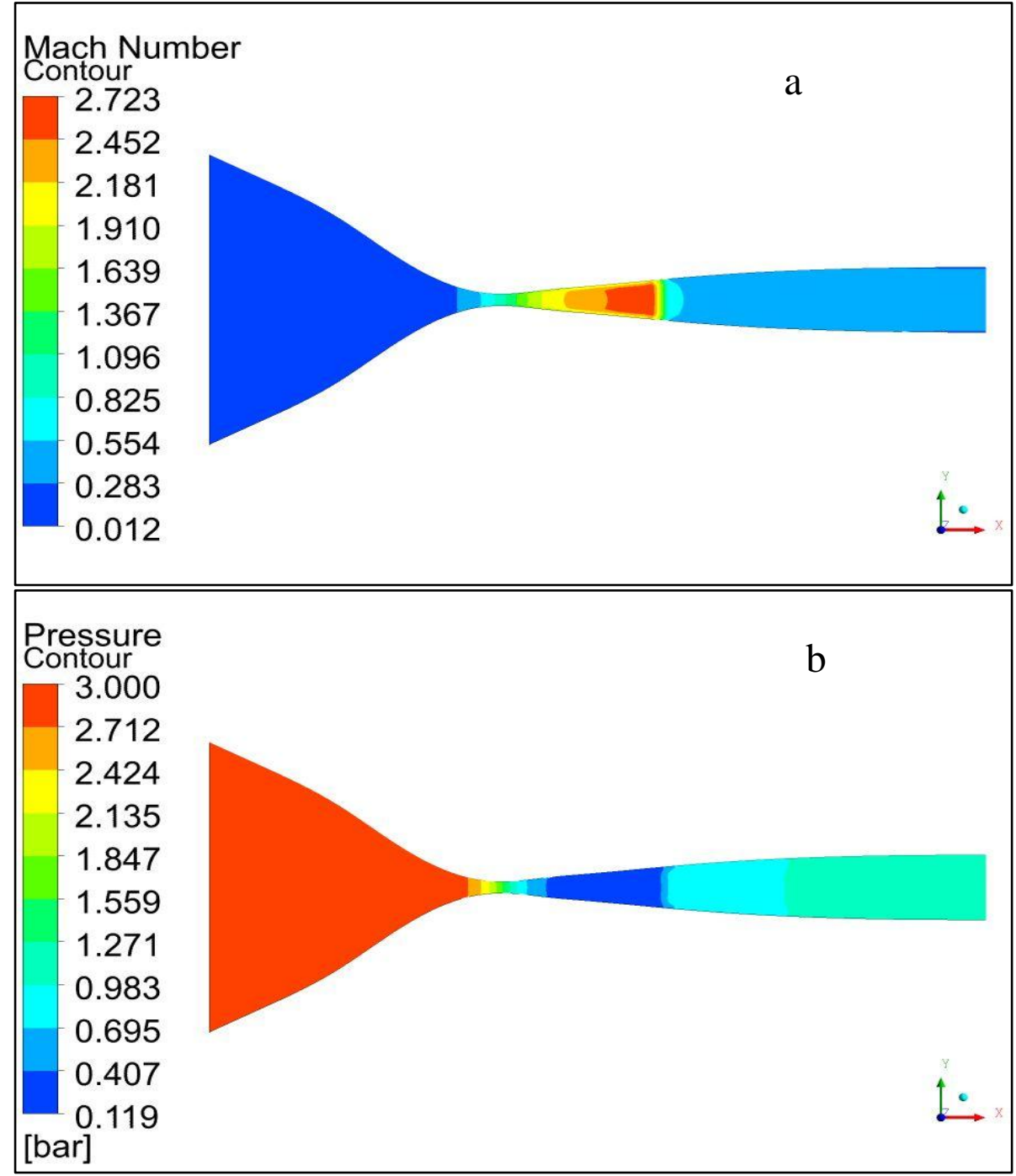

Figure (14): ( $\mathrm{P}_{\mathrm{o}}=3$ bar, $\mathrm{P}_{\mathrm{b}}=1$ bar).

(a) Mach No. contour. (b) Static pressure contour. 


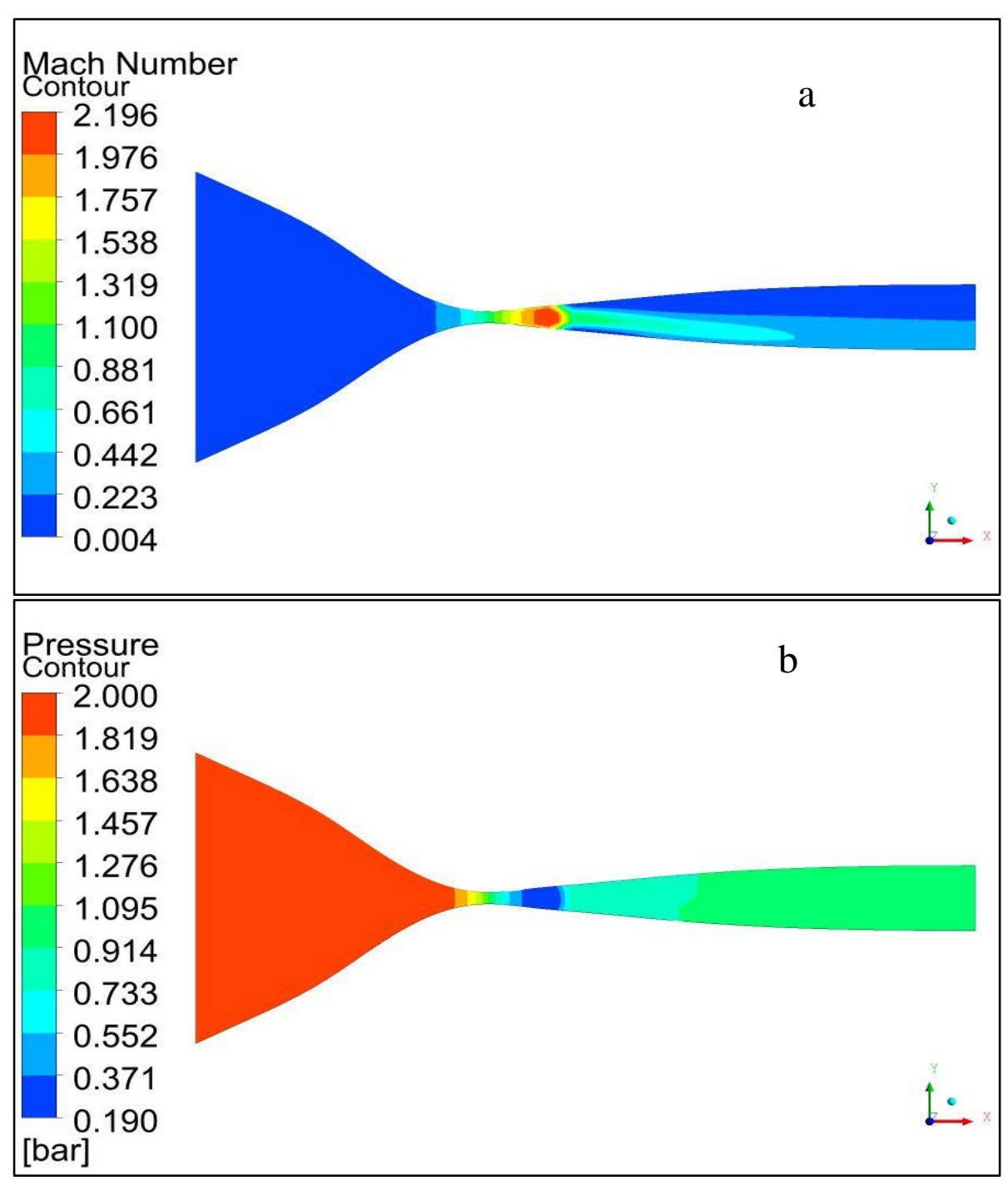

Figure (15): $\left(\mathrm{P}_{\mathrm{o}}=2\right.$ bar, $\mathrm{P}_{\mathrm{b}}=1$ bar).

(a) Mach No. contour. (b) Static pressure contour. 


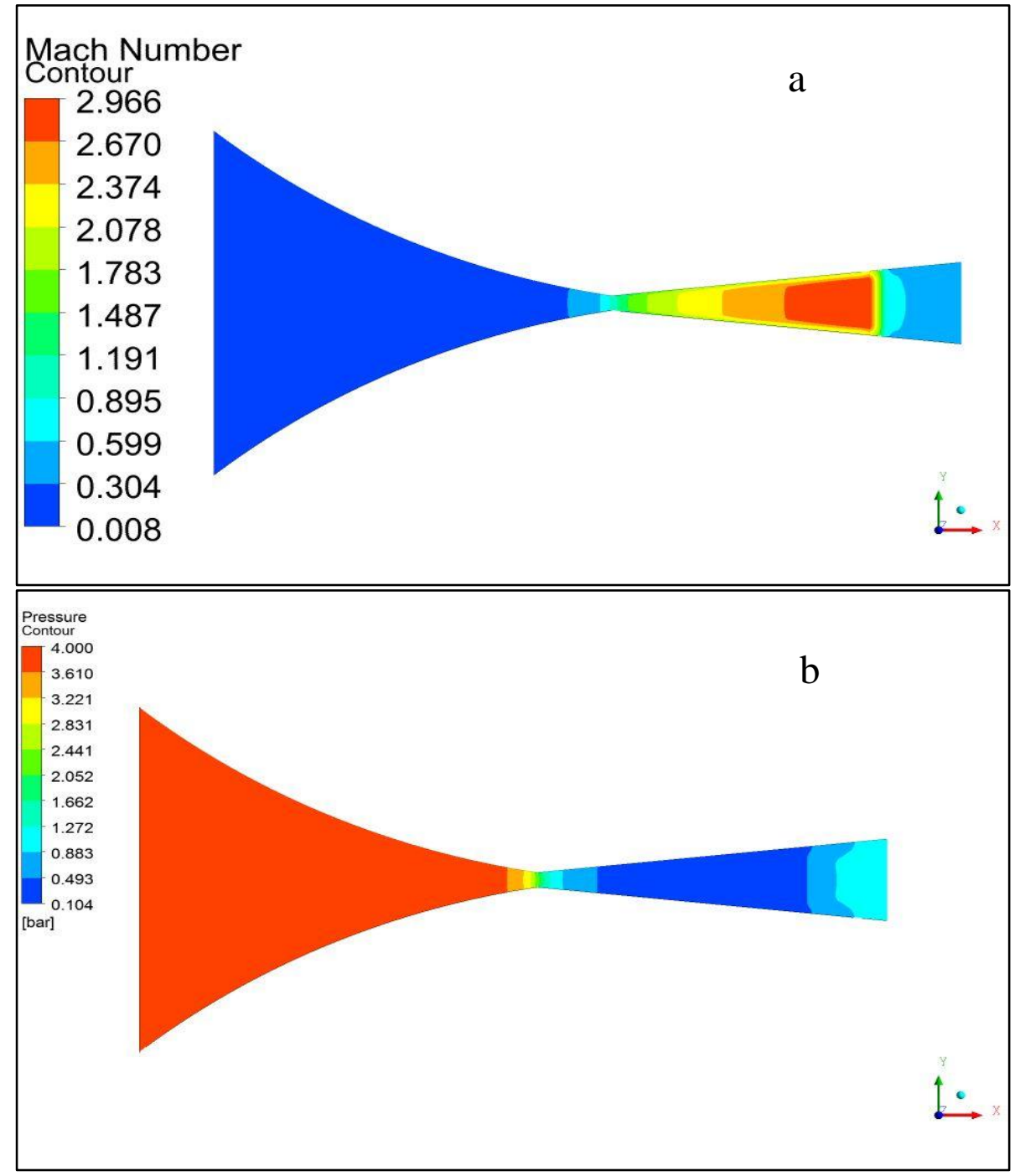

Figure (16): $\left(\mathrm{P}_{\mathrm{o}}=4\right.$ bar, $\mathrm{P}_{\mathrm{b}}=1$ bar).

(a) Mach No. contour. (b) Static pressure contour. 


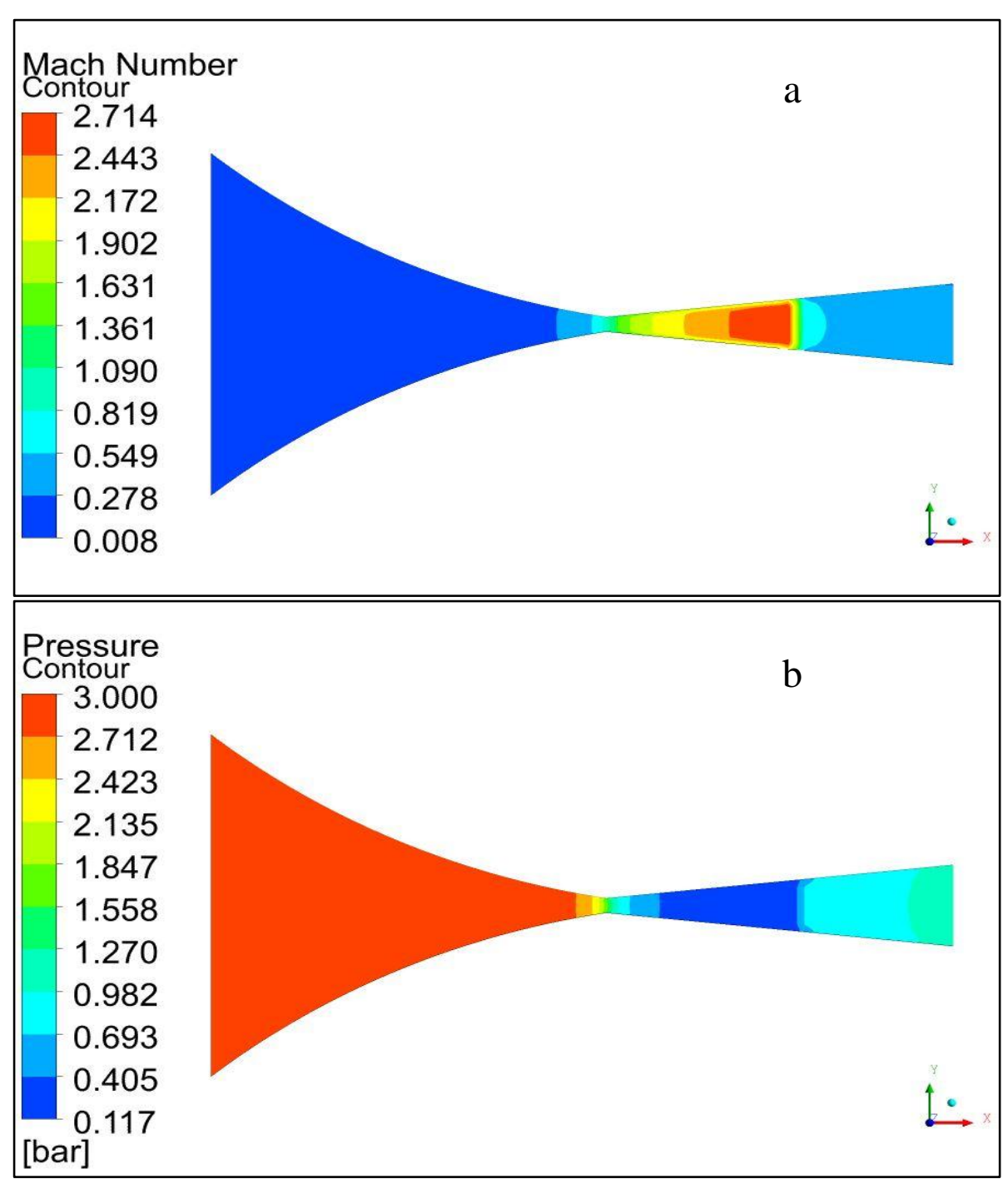

Figure (17): ( $\mathrm{P}_{\mathrm{o}}=3$ bar, $\mathrm{P}_{\mathrm{b}}=1$ bar).

(a) Mach No. contour. (b) Static pressure contour. 


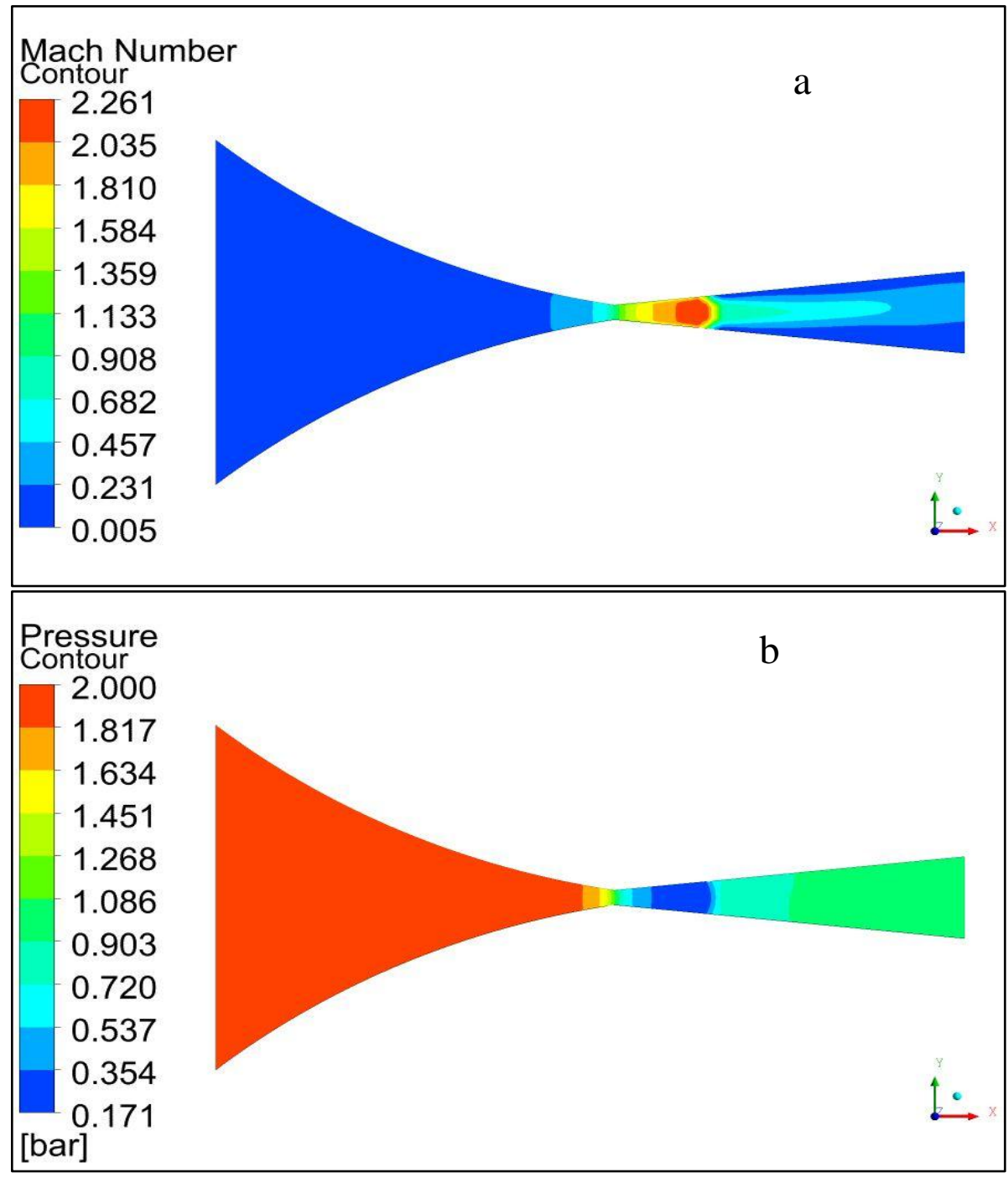

Figure (18): $\left(\mathrm{P}_{\mathrm{o}}=2\right.$ bar, $\mathrm{P}_{\mathrm{b}}=1$ bar).

(a) Mach No. contour. (b) Static pressure contour. 


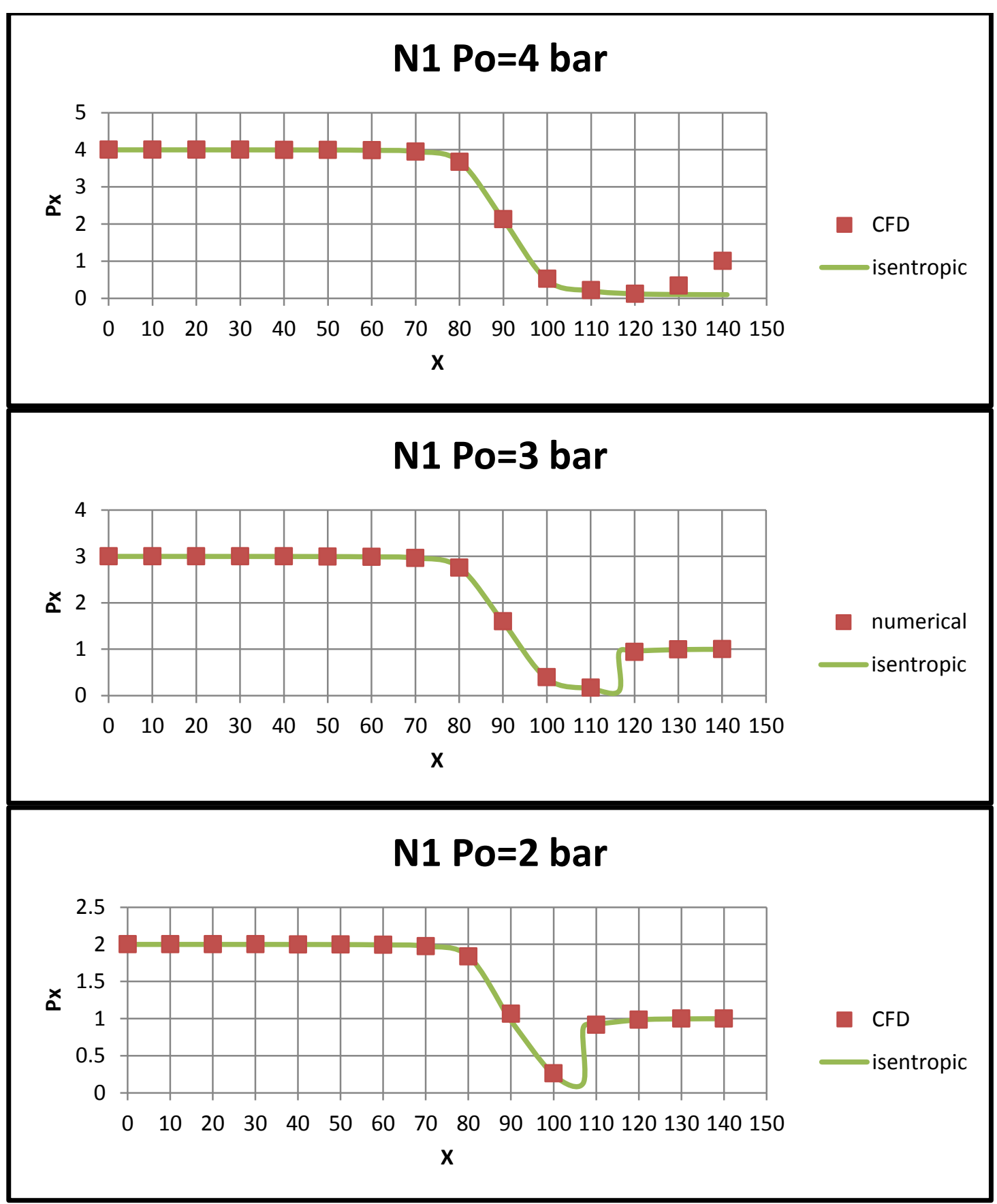

Figure (19): Iesentropic and CFD comparesion of static pressure distribution along nozzle centerline (N1). 


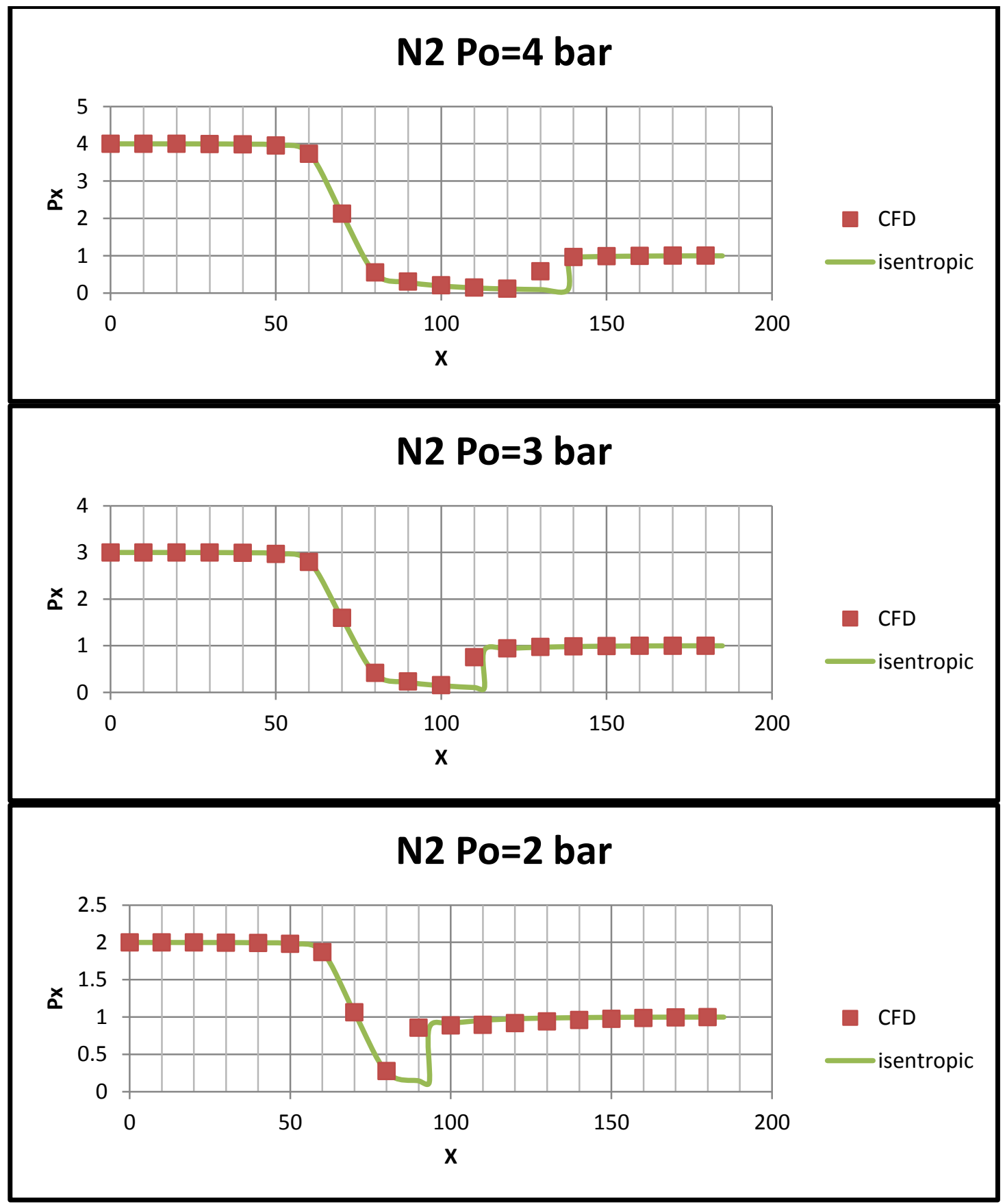

Figure (20): Iesentropic and CFD comparesion of static pressure distribution along nozzle centerline $(\mathrm{N} 2)$. 


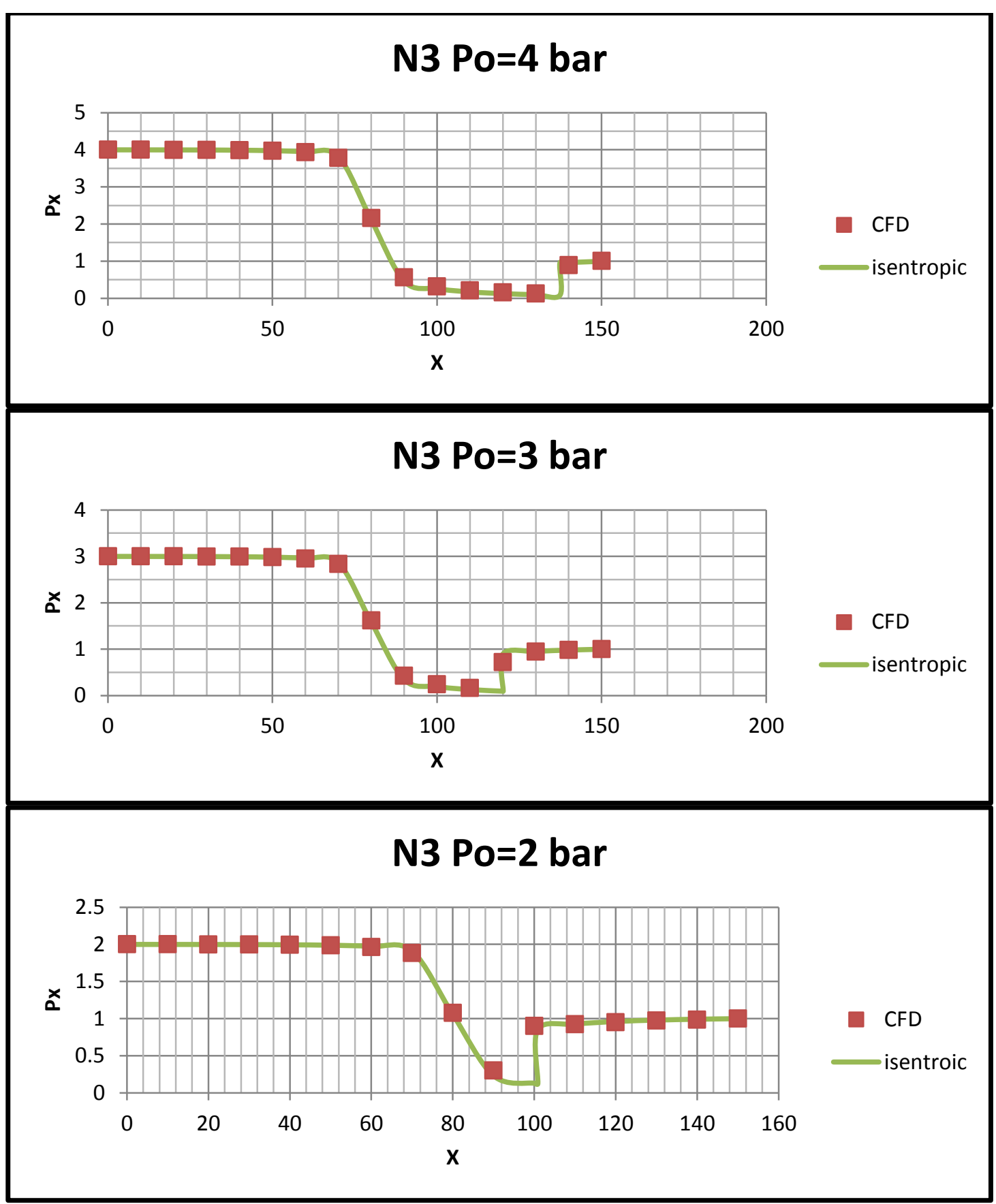

Figure (21): Iesentropic and CFD comparesion of static pressure distribution along nozzle centerline (N3). 


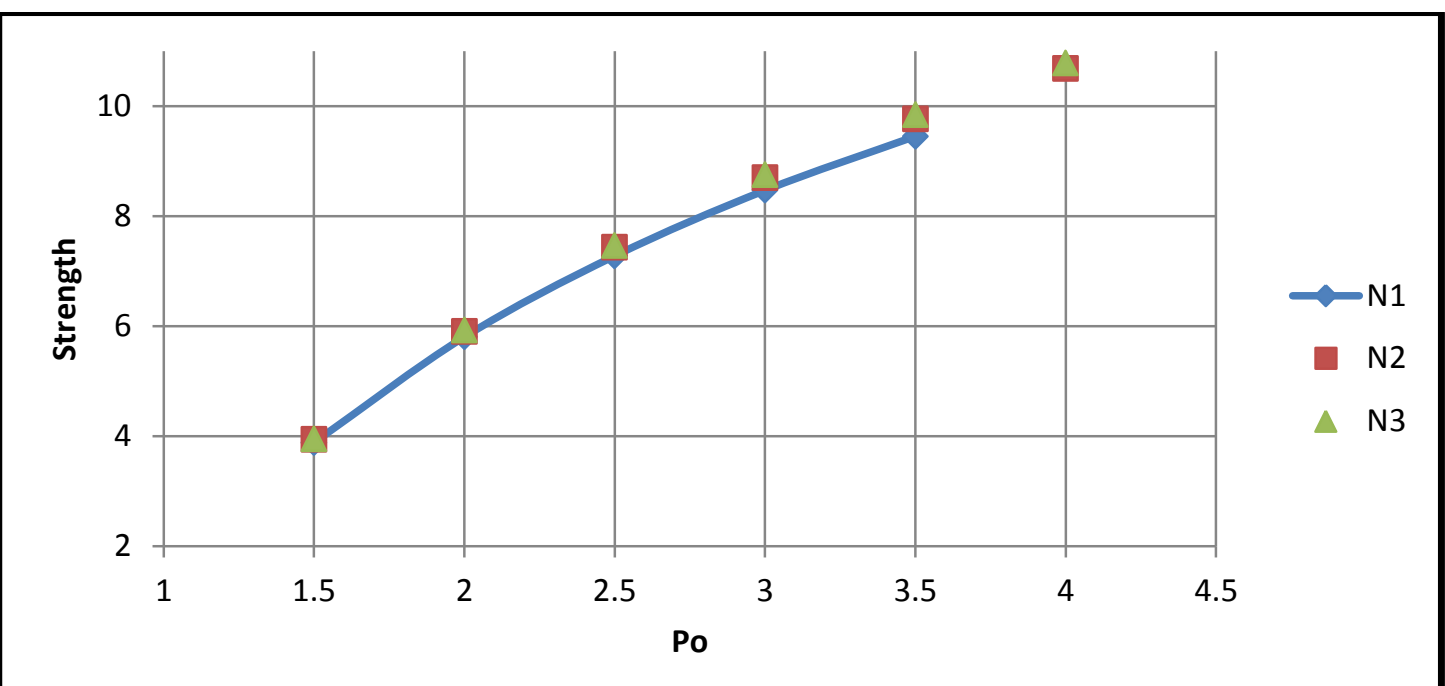

Figure (22): the strength of the shockwave of each nozzle against the inlet total pressure.

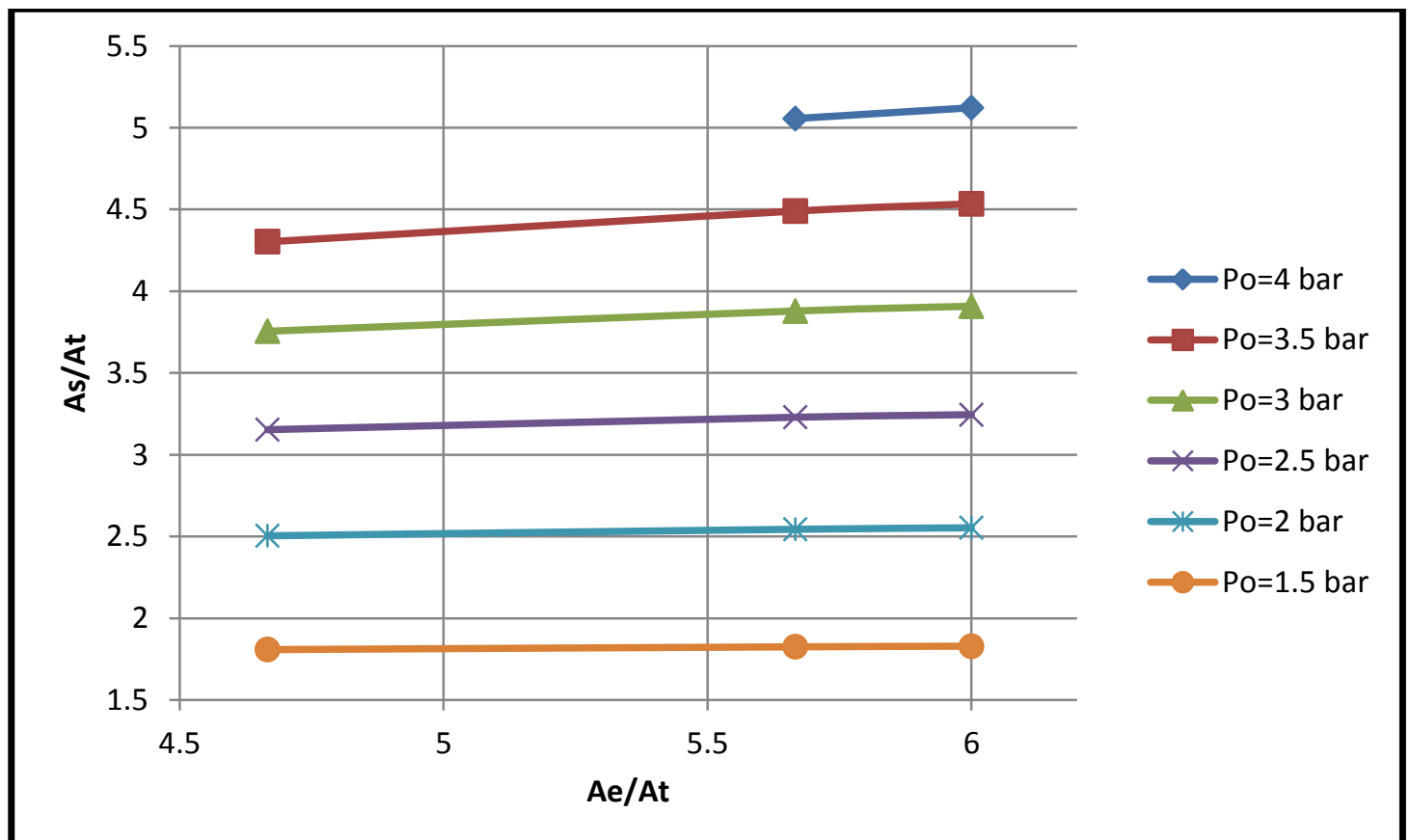

Figure (23): the shockwave location versus exist area ratio for each nozzle. 

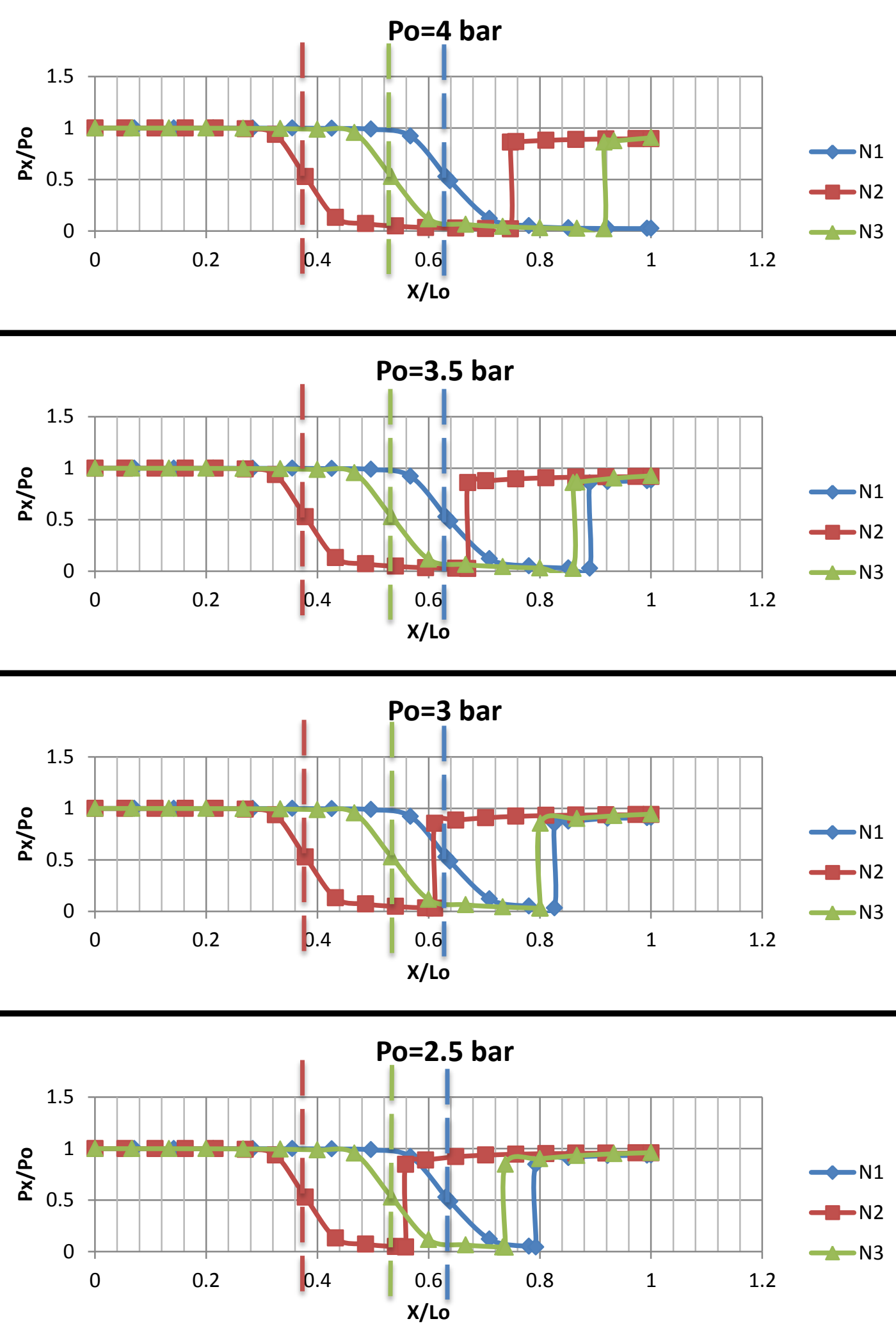

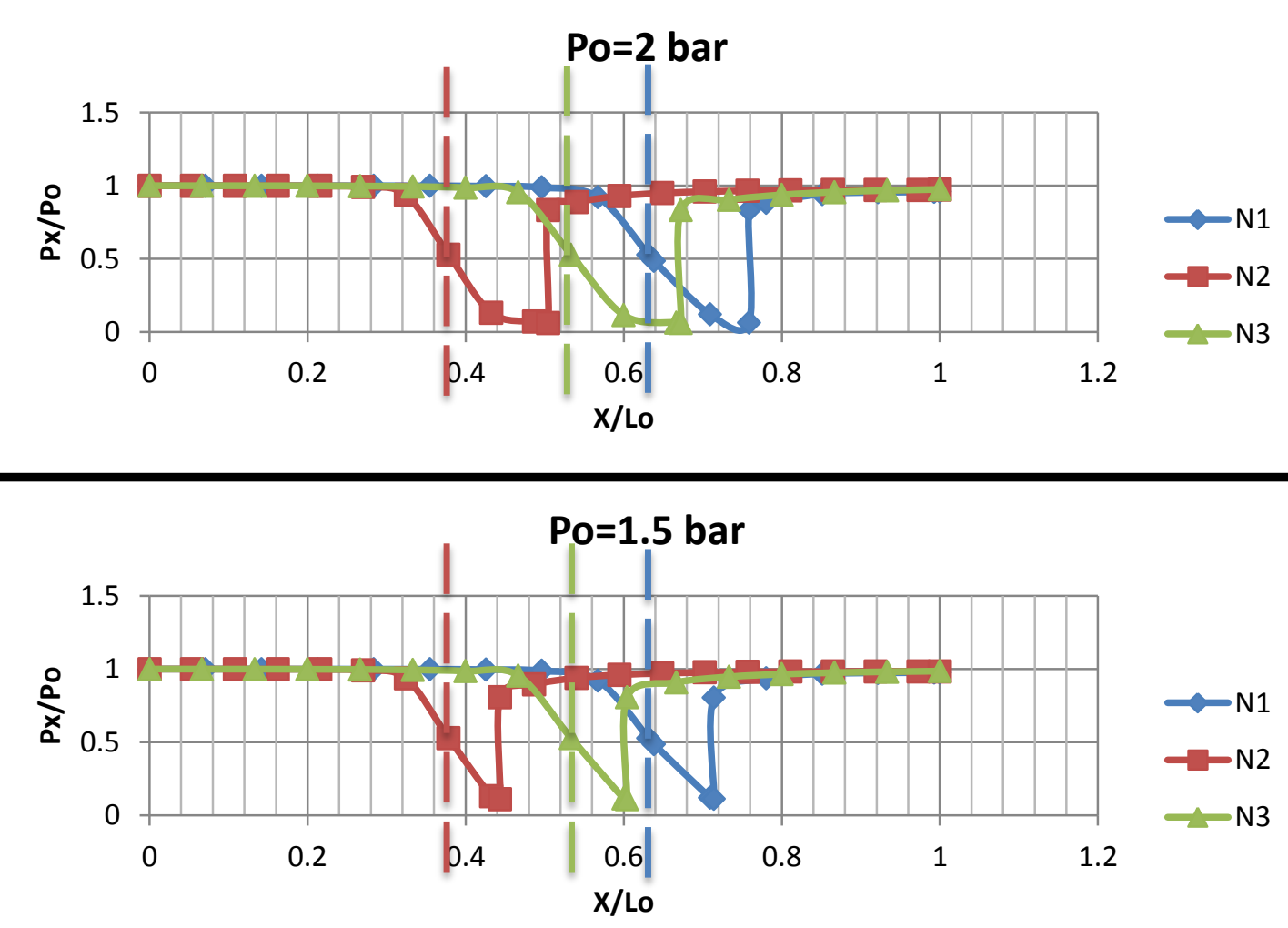

Figure (24): Comparison between isentropic flow of the three nozzles at different inlet pressures.

Table (1): Analysis Procedure

\begin{tabular}{|c|c|}
\hline Prodcedure & Details \\
\hline Setup general & $\begin{array}{l}\text { Type: density based } \\
\text { Velocity formation: absolut. } \\
\text { Time: steady state. } \\
\text { 2D Space: planner }\end{array}$ \\
\hline Models & $\begin{array}{l}\text { Energy: on } \\
\text { Viscous: realizable K- } \varepsilon\end{array}$ \\
\hline Materials & Fluid: air, desity: ideal gas \\
\hline $\begin{array}{l}\text { Cell zone } \\
\text { conditions }\end{array}$ & Operationg condition: $0 \mathrm{pa}$ \\
\hline $\begin{array}{l}\text { Boundary } \\
\text { conditions }\end{array}$ & $\begin{array}{l}\text { Inlet pressure: ( } 4 \text { bar to } 2 \text { bar). } \\
\text { Outlet pressure: ( } 1 \text { bar). } \\
\text { Temperature: }(300 \mathrm{~K}) \text {. }\end{array}$ \\
\hline Solution & $\begin{array}{l}\text { Solution methods: implicit formulation. } \\
\text { Cournt number: } 5 \\
\text { Solution initialization: hybrid initialization. } \\
\text { Run calculation: } 5000 \text { number of iteration. }\end{array}$ \\
\hline
\end{tabular}




\section{REFERENCES}

Nazar Muneam Mahmood," Simulation of Back Pressure Effect on Behavior of Convergent Divergent Nozzle", Diyala Journal of Engineering Sciences, Vol.06, No.01, pp.105-120, [March 2013].

Biju Kuttan, Msajesh,"Optimization of Divergent Angle of Rocket Engine Nozzle Using Computational Fluid Dynamics", The International Journal of Engineering and Science (Ijes), Vol.2, Issue.2, pp.196-207, (2013).

Kunal Pansari and S.A.K Jilani,"Numerical Investigation of the Performance of Convergent Divergent nozzle", International Journal of Modern Engineering Research (IJ MER), Vol.3, Issue.5, pp.2662-2666, (Oct 2013).

P. Parthiban, M, Robert Sugaxadoss and T. Ambikap," Design and Anylysis of Rocket Engine Nozzle by using CFD and Optimization of Nozzle Parameters", a Peer Reviewed International Journal, Vol.3, Issue.5, pp. 312-319, (2015).

Shyamshankar, M.B Sankar.V, "Investigation on Divergent Exit Curvature Effect on Nozzle Pressure Ratio of Supersonic Convergent Divergent Nozzle", Int. Journal of Engineering Research and Applications, Vol.5, Issue. 5, pp.164-172 (May 2015).

B. V. V. Naga Sudhakar Mohan and MD Touseef Ahmad,"Modeling and Simulation of Convergent Divergent Nozzle using Computational Fluid Dynamics", International Research Journal of Engineering and Technology, Vol.03, Issue.08, pp. 346-350 (Aug 2016).

Syed Sameer and Kal Yana Kumar," CFD Analysis of Convergent Divergent and Contour Nozzle", International Journal of Mechanical Engineering and Technology (IJMET), Vol.8, Issue.8, PP.670677, (2017).

Esam Jassim, ," Numerical Investigation of Nozzle Shape Effect on Shock Wave in Natural Gas Processing", Ph. D. Thesis ,Faculty of Engineering and Applied Science Prince Mohammad University, Al-Khobar Eastern Province, Kingdom of Sauidi Arabia.

Hussein Wheeb Mashi and Samir Ali Alrabii,"Drop Diameter Prediction Model For Liquid Phase Dispersion in a Supersonic Nozzle With Wet Steam Flow", Journal of Engineering and Development, Vol.16, No.4, pp. 363-389, [Dec 2012].

James John and Theo Keith, 'Gas Dynamics', third edition. Pearson education international 2006.

ANSYS FLUENT 15.0 Theory guide, http:// www.ansys.com, November 2013. 